\title{
Estimating the Greenland ice sheet surface mass balance contribution to future sea level rise using the regional atmospheric climate model MAR
}

\author{
X. Fettweis ${ }^{1}$, B. Franco ${ }^{1}$, M. Tedesco ${ }^{2}$, J. H. van Angelen ${ }^{3}$, J. T. M. Lenaerts ${ }^{3}$, M. R. van den Broeke ${ }^{3}$, and H. Gallée ${ }^{4}$ \\ ${ }^{1}$ Department of Geography, University of Liege, Liege, Belgium \\ ${ }^{2}$ The City College of New York, The City University of New York, New York, NY, USA \\ ${ }^{3}$ Institute for Marine and Atmospheric research (IMAU), Utrecht University, the Netherlands \\ ${ }^{4}$ Laboratoire de Glaciologie et Géophysique de l'Environnement (LGGE), Grenoble, France
}

Correspondence to: X. Fettweis (xavier.fettweis@ulg.ac.be)

Received: 17 July 2012 - Published in The Cryosphere Discuss.: 2 August 2012

Revised: 21 February 2013 - Accepted: 22 February 2013 - Published: 14 March 2013

\begin{abstract}
To estimate the sea level rise (SLR) originating from changes in surface mass balance (SMB) of the Greenland ice sheet (GrIS), we present 21st century climate projections obtained with the regional climate model MAR (Modèle Atmosphérique Régional), forced by output of three CMIP5 (Coupled Model Intercomparison Project Phase 5) general circulation models (GCMs). Our results indicate that in a warmer climate, mass gain from increased winter snowfall over the GrIS does not compensate mass loss through increased meltwater run-off in summer. Despite the large spread in the projected near-surface warming, all the MAR projections show similar non-linear increase of GrIS surface melt volume because no change is projected in the general atmospheric circulation over Greenland. By coarsely estimating the GrIS SMB changes from GCM output, we show that the uncertainty from the GCM-based forcing represents about half of the projected SMB changes. In 2100, the CMIP5 ensemble mean projects a GrIS SMB decrease equivalent to a mean SLR of $+4 \pm 2 \mathrm{~cm}$ and $+9 \pm 4 \mathrm{~cm}$ for the RCP (Representative Concentration Pathways) 4.5 and RCP 8.5 scenarios respectively. These estimates do not consider the positive melt-elevation feedback, although sensitivity experiments using perturbed ice sheet topographies consistent with the projected SMB changes demonstrate that this is a significant feedback, and highlight the importance of coupling regional climate models to an ice sheet model. Such a coupling will allow the assessment of future response of both
\end{abstract}

surface processes and ice-dynamic changes to rising temperatures, as well as their mutual feedbacks.

\section{Introduction}

The surface mass balance (SMB) of the Greenland ice sheet (GrIS) can be approximated in first order by the water mass gained by snowfall minus the mass lost by meltwater run-off. The mass gain from rainfall as well as the mass loss from erosion, from the net water fluxes (e.g. the sum of the evaporation, sublimation, deposition and condensation) and from the wind (blowing snow) appear to be negligible compared to snowfall and run-off (Box et al., 2004; Lenaerts et al., 2012).

A warmer climate will lead to an ice sheet surface thickening inland, due to increased solid precipitation, and a thinning along the GrIS periphery, due to increased surface melt. It is expected that the increase in meltwater run-off is only partly compensated by the increase in (winter) snowfall (Gregory and Huybrechts, 2006; IPCC, 2007; Fettweis et al., 2008; van Angelen et al., 2013; Rae et al., 2012), a phenomenon that has already been observed in recent years with anomalously low SMB on the GrIS (van den Broeke et al., 2009; Tedesco et al., 2011; Rignot et al., 2011). Rising temperatures also increase the ratio of liquid to solid precipitation, which wets the snowpack and in turn could further enhance surface melt by lowering the albedo. However, as we will see, most of the rainfall increase occurs over bare ice areas in the ablation zone, with hardly any 
affect on the surface albedo. The extra liquid water from rain will just run off the ice sheet to the ocean along with the produced surface meltwater.

Besides impacting surface processes, increasing surface temperatures also has its feedback on ice dynamics. Current estimates on increased mass loss from the GrIS over the last two decades, are roughly equally partitioned between increased meltwater run-off and increased discharge from the outlet glaciers. (van den Broeke et al., 2009; Rignot et al., 2011). The dynamical response of the ice dynamic to further increased surface melt reaching the bedrock (Zwally et al., 2002) is still uncertain. However, recent observations suggest that the latter is not a significant component of the total uncertainty in future sea level rise (Nick et al., 2009; Rignot et al., 2011; Sundal et al., 2011). The acceleration in flow of tidewater glaciers, due to large melting at the calving front, is expected to decline in the future as the glaciers retreat above sea level (Goelzer et al., 2012), and makes meltwater run-off the dominant contributor to sea level rise from the GrIS. A preliminary objective, addressed in this study, is to provide the best possible estimate of future SMB and associated surface meltwater run-off. Such run-off contributes both to Sea Level Rise (SLR) and may as well affect the North Atlantic thermohaline circulation (THC) (Swingedouw et al., 2009; Weijer et al., 2012).

The contribution to sea level rise originating from a decrease in GrIS SMB by the end of this century is currently estimated at $0-15 \mathrm{~cm}$ SLR with respect to the year 2000 (Gregory and Huybrechts, 2006; IPCC, 2007; Fettweis et al., 2008; Graversen et al., 2010; Mernild et al., 2010; Vizcaino et al., 2010; Bengtsson et al., 2011; Franco et al., 2011). However, despite the direct impact of GrIS melt on the global climate, large uncertainties remain in these estimations. One of the reasons for this is the fact that most of the current studies are based on the output of atmosphere-ocean general circulation models (GCMs) produced at a coarse horizontal spatial resolution $(300 \mathrm{~km})$. This limits their capabilities to capture SMB changes on the narrow ablation zone of the GrIS. Moreover, the GCMs usually lack a realistic representation of the snow/firn/ice processes that occur within the upper ice sheet snowpack.

Because of these GCM shortcomings, regional atmospheric climate models (RCMs) with a sophisticated snow model are an ideal tool to understand the current Greenland ice sheet climate and to quantify changes in the near future. The high spatial resolution and enhanced physics of RCMs can be optimised to study a specific region and its processes. It is true that RCMs neglect the feedbacks coming from the GrIS depletion affecting the global climate at long timescales (1-kyrs), as the GCMs (Swingedouw et al., 2009; Hakuba et al., 2012). Moreover, the elevation-climate feedback from the GrIS (Helsen et al., 2012), which becomes significant on the timescale of 100-yr is omitted if the RCM is not coupled with an ice sheet model, as we will see later.
The regional climate model MAR (Modèle Atmosphérique Régional), fully coupled with a snow model and extensively validated to simulate the SMB of the Greenland ice sheet (Lefebre et al., 2003, 2005; Fettweis, 2007; Fettweis et al., 2005, 2011b; Franco et al., 2012), has been developed to study the Greenland climate and run at a relatively high spatial resolution $(25 \mathrm{~km})$.

Previous studies (Mernild et al., 2008, 2010; Rae et al., 2012) have not generally accounted for snow metamorphosis and the associated temperature-albedo feedbacks, which are included in MAR. The boundary conditions for MAR are provided by several GCMs included in the IPCC ( Intergovernmental Panel on Climate Change ) fifth assessment report (AR5). This work fits into the ICE2SEA project (http: //www.ice2sea.eu) of the 7th Framework Program (FP7), which aims to improve the projections of future sea level rise due to the contribution of melt from land-based ice.

After a brief description of the MAR model in Sect. 2, Sect. 3 compares the MAR output obtained with ERAInterim reanalysis forcing data over the period 1980-2012 with those obtained from MAR forced by the selected GCMs. In Sect. 4, we analyse future SMB projections. Section 5 describes the sensitivity of the SMB components to a fixed temperature anomaly independently from the forcing GCM and scenario. Finally, in Sect. 6, we discuss future projections of GrIS SMB decrease based on 30 GCMs from the CMIP5 (Coupled Model Intercomparison Project Phase 5) database as well as the uncertainties in our estimations.

\section{Data}

\subsection{The MAR model}

The model used here is the regional climate model MAR coupled to the 1-D surface vegetation atmosphere transfer scheme SISVAT (Soil Ice Snow Vegetation Atmosphere Transfer) (Gallée and Schayes, 1994). The snow-ice part of SISVAT, based on the CEN (Centre d'Etudes de la Neige) snow model called CROCUS (Brun et al., 1992), is a onedimensional multilayered energy balance model that determines the exchanges between the sea ice, the ice sheet surface, the snow-covered tundra, and the atmosphere. It allows meltwater refreezing and snow metamorphosis, influencing the transformation of snow to ice and the surface albedo using the CROCUS formulations (Brun et al., 1992; Gallée et al., 2001). The MAR physical parameterisations used here are the ones from Fettweis et al. (2011b), which are calibrated to agree with the satellite derived melt extent over 1979-2009. The snowpack initialization is described in Fettweis et al. (2005) and a spatial resolution of $25 \mathrm{~km}$ is used here.

SISVAT does not include a 3-D ice sheet model and consequently Greenland maintains a fixed height and extent through the simulations. Since the version of Fettweis 
et al. (2011b) used in the MAR future projections made for ICE2SEA (Rae et al., 2012), a new tundra/ice mask based on the Greenland land surface classification mask from Jason Box (http://bprc.osu.edu/wiki/Jason_Box_Datasets) is prescribed and the smoothing of the Bamber et al. (2001) based topography is reduced by a factor 2 in the CMIP5 forced MAR simulations. According to Vernon et al. (2012), this alters a little the MAR results, as discussed in the Supplement. The ECMWF (European Centre for Medium-Range Weather Forecasts) reanalysis-forced MAR simulations over 1980-2010 are used to homogenise the results by crosscalibration when values of SMB components are given at the scale of the whole ice sheet, since results using different ice sheet masks and topographies are presented here.

By testing MAR at different spatial resolutions (from 15 to $50 \mathrm{~km}$ ) over the period 1990-2010, Franco et al. (2012) have shown that the spatial resolution does not affect the interannual variability of the MAR SMB components if they are integrated at the scale of the whole ice sheet. We can then assume that the GrIS integrated SMB changes are independent of the spatial resolution used in MAR. However, at local scales, with the aim of forcing ice sheet models, which need SMB inputs at very high resolution, the higher the resolution is, the better the spatial variability of SMB will be resolved for forcing ice sheet models (Lucas-Picher et al., 2012). According to Franco et al. (2012), a resolution of $10-15 \mathrm{~km}$ is generally needed to resolve the steep slopes in the vicinity of the ice sheet margin. Here, a resolution of $25 \mathrm{~km}$ is used to save computer time, but as shown by Franco et al. (2012), the MAR $25 \mathrm{~km}$ results can be used to extrapolate the SMB at resolutions of $10-15 \mathrm{~km}$ by using interpolation based on local SMB gradients.

\subsection{Simulations}

To study the current climate, the ERA-40 reanalysis (19581978) and the ERA-Interim reanalysis (1979-2012) from ECMWF are used to initialize the meteorological fields at the beginning of the MAR simulation in September 1957 and to force MAR every 6-h at its lateral boundaries. The sea surface temperature (SST) and the sea ice cover (SIC) are also prescribed by the ECMWF reanalysis.

The MAR reference state, forced by the ERA-Interim re-

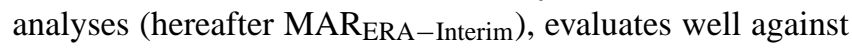
the SMB (Tedesco et al., 2011; Franco et al., 2012; Rae et al., 2012; Vernon et al., 2012), the (near-)surface temperature (Lefebre et al., 2005; Fettweis et al., 2011b; Tedesco et al., 2012; Box et al., 2012; Rae et al., 2012), the downward shortwave radiation (Box et al., 2012), the melt extent (Fettweis et al., 2006, 2011b) and the albedo (Lefebre et al., 2003; Fettweis et al., 2005). In its validation, MAR is comparable to another RCM: RACMO2 (Regional Atmospheric Climate Model) (van Angelen et al., 2012a; Lenaerts et al., 2012). Its simulations will be compared later to show that the trends in our future projections are independent of the used
RCM. That is why, in a lack of SMB observations at the scale of the whole ice sheet, the ERA-Interim forced MAR (refer-

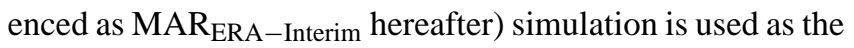
reference run in this manuscript.

For computing future projections, we force MAR with 6-hly outputs (temperature, wind, humidity and surface pressure) from four GCMs (BCC-CSM1-1, Beijing Climate Center Climate System Model; CanESM2, Canadian Earth System Model; NorESM1-M, Norwegian Climate Center's Earth System Model; and MIROC5, Model for Interdisciplinary Research on Climate) of the CMIP5 database and from two GCMs (ECHAM5 and HadCM3, Hadley Centre coupled model) used by the FP7 ICE2SEA project (see Table 1). The version of ECHAM5 and HadCM3 is intermediate between the one used in the CMIP3 and CMIP5 databases (Rae et al., 2012). As for the ECMWF-forced simulations, daily SST and SIC from GCMs are used to force the ocean surface conditions in SISVAT.

The two scenarios of future greenhouse gas (GHG) concentration increase used in this study, called RCP for representative concentration pathways (Moss et al., 2010) are

- RCP 4.5: mid-range scenario corresponding to a linear increase of radiative forcing towards $+4.5 \mathrm{~W} \mathrm{~m}^{-2}$ until 2080, and stabilizing afterwards. This scenario corresponds to an increase of the atmospheric greenhouse gas concentration during the 21 st century to a level of $\sim 650 \mathrm{CO}_{2}$ equivalent p.p.m. by 2100 .

- RCP 8.5: high-end scenario corresponding to a radiative forcing of $>+8.5 \mathrm{~W} \mathrm{~m}^{-2}$ by 2100 . This scenario corresponds to an increase of the atmospheric GHG concentration during the 21 st century to a level of $>1370 \mathrm{CO}_{2}$ equivalent p.p.m. by 2100 .

As a comparison and for reader's convenience, results of RCP $6.0\left(\sim 850 \mathrm{CO}_{2}\right.$ equivalent p.p.m. by 2100$)$ and SRES A1B $\left(\sim 860 \mathrm{CO}_{2}\right.$ equivalent p.p.m. by 2100$)$ scenarios are also reported (see Table 1).

\section{Evaluation over current climate}

The aim of this section is to evaluate the ability of the CMIP5 GCMs to simulate the present-day climate (general circulation) over Greenland in respect to the ERA-Interim over 1980-1999. Moreover, the present-day SMB (19801999) simulated by MAR, forced by three chosen GCMs from the CMIP5 database, are going to be compared to

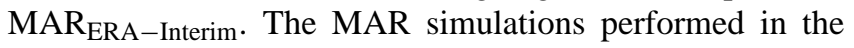
framework of the ICE2SEA project are also evaluated for comparison, whereas they are not used in our future SLR projections. Only the period 1980-1999 covered by ERAInterim and used by the IPCC (2007) as the reference period over current climate is investigated here. Comparisons on longer time periods are available in the Supplement. 


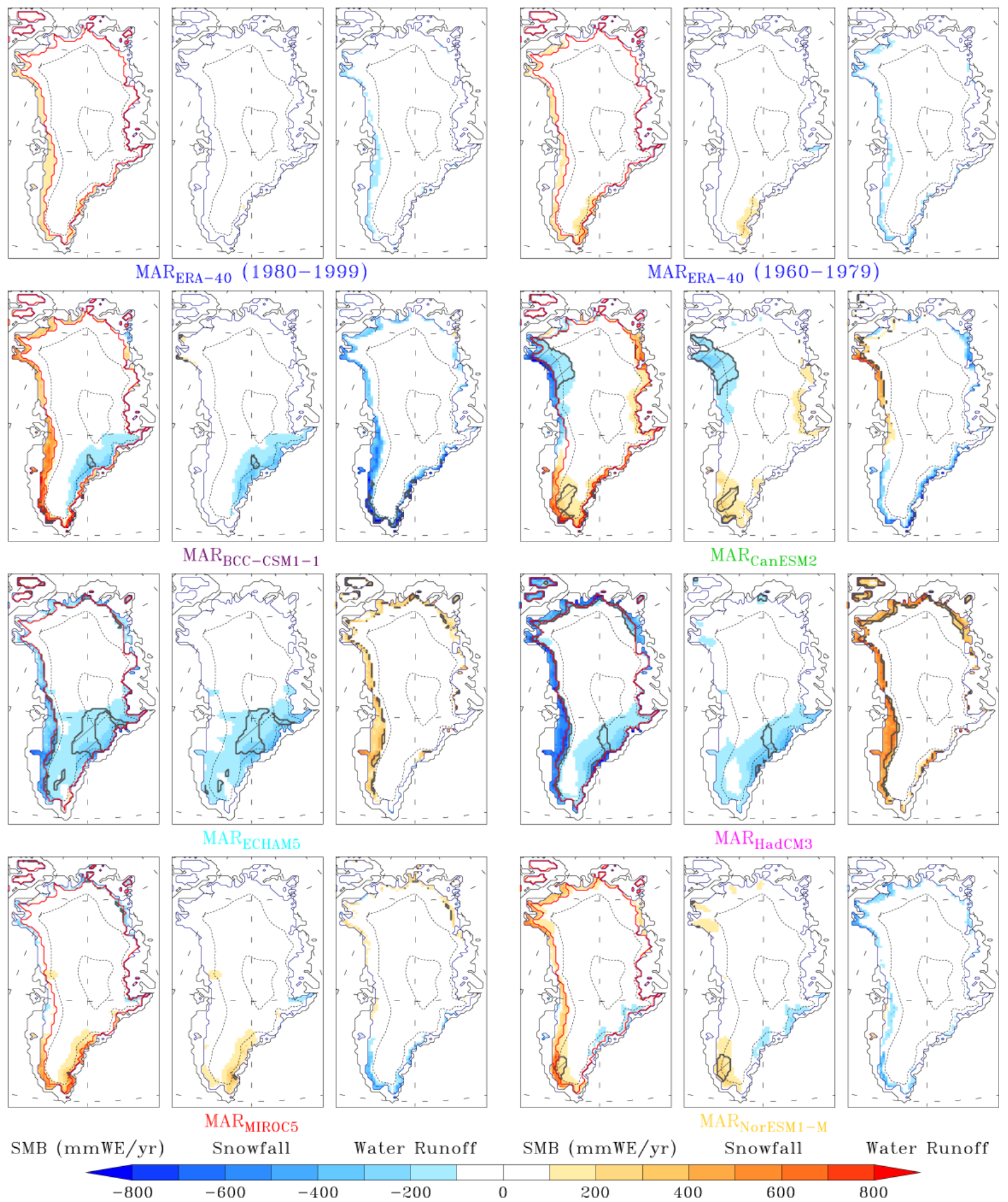

Fig. 1. Mean anomalies of the annual SMB, snowfall and water run-off with respect to the ERA-Interim forced MAR simulation over

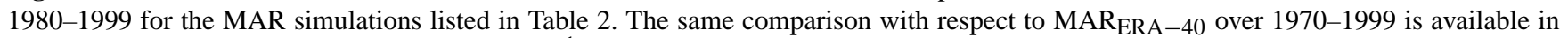

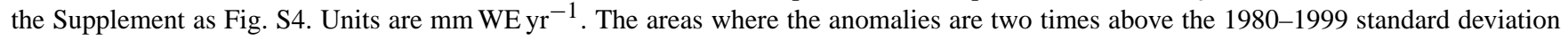

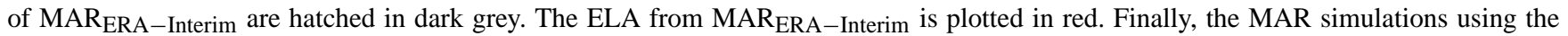

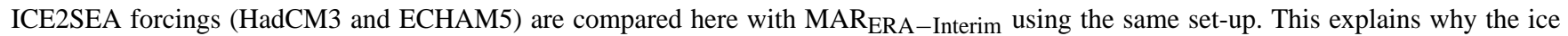
sheet mask here is a bit different in respect to the CMIP5 forced MAR simulations. 
Table 1. Summary of the different forcings and scenarios used in the MAR simulations.

\begin{tabular}{|c|c|c|c|}
\hline Boundaries RCM forcing & Institutes, Country & Period & Scenario \\
\hline ERA-40 reanalysis & ECMWF, UK & 1957-2001 & \\
\hline ERA-Interim reanalysis & ECMWF, UK & 1979-2012 & \\
\hline BCC-CSM1-1 (CMIP5) & Beijing Climate Center, China & 1975-1999 & Historical \\
\hline BCC-CSM1-1 (CMIP5) & Beijing Climate Center, China & 2075-2099 & RCP85 \\
\hline CanESM2 (CMIP5) & $\begin{array}{l}\text { Canadian Centre for Climate } \\
\text { Modelling and Analysis, Canada }\end{array}$ & $1965-2005$ & Historical \\
\hline CanESM2 (CMIP5) & $\begin{array}{l}\text { Canadian Centre for Climate } \\
\text { Modelling and Analysis, Canada }\end{array}$ & $2006-2100$ & RCP45 and RCP85 \\
\hline ECHAM5 (ICE2SEA) & $\begin{array}{l}\text { Max Planck Institute for } \\
\text { Meteorology, Germany }\end{array}$ & 1980-1999 & SRES 20C3M \\
\hline ECHAM5 (ICE2SEA) & $\begin{array}{l}\text { Max Planck Institute for } \\
\text { Meteorology, Germany }\end{array}$ & 2000-2099 & SRES A1B \\
\hline HadCM3 (ICE2SEA) & Met Office Hadley Centre, UK & 1980-1999 & SRES 20C3M \\
\hline HadCM3 (ICE2SEA) & Met Office Hadley Centre, UK & 2000-2099 & SRES A1B \\
\hline MIROC5 (CMIP5) & The University of Tokyo, Japan & $1965-2005$ & Historical \\
\hline MIROC5 (CMIP5) & The University of Tokyo, Japan & $2006-2100$ & RCP45 and RCP85 \\
\hline NorESM1-M (CMIP5) & Norwegian Climate Centre, Norway & $1965-2005$ & Historical \\
\hline NorESM1-M (CMIP5) & Norwegian Climate Centre, Norway & $2006-2100$ & $\begin{array}{l}\text { RCP26, RCP45, } \\
\text { RCP60 and RCP85 }\end{array}$ \\
\hline
\end{tabular}

An evaluation only over 20 years could be litigious because the ERA-Interim based time series could contain significant decadal variability affecting the general circulation over Greenland, which cannot be temporally matched to the decadal variability in the GCM forced simulations. However, as shown by Fettweis et al. (2013), both CMIP5 GCMs and reanalysis do not simulate changes in the North Atlantic Oscillation (NAO) and in the general circulation over the second half of the twentieth century. This means that the climate over Greenland in the 1960s and 1970s is comparable to 19801999 (see Fig. 1) and that the GrIS SMB is relatively stable from the beginning of the 1960s until the end of the 1990s (Rignot et al., 2008; van den Broeke et al., 2009). Therefore, extending the comparison over 1960-1999 using ERA-40 as reference instead of ERA-Interim over 1980-1999 does not affect the comparison as shown in the Supplement. The reference simulation is not extended to the last decade (not representative of the average climate over Greenland) as during the 2000s Greenland has become significantly warmer (and drier) as a result of a change in the NAO.

A good representation of the current climate is a necessary but not the only condition needed to realistically simulate future climate changes. A model that fails to reproduce the current climate generates projections that lack in reliability and validity since the response of the climate to a warming is not linear. That is particularly true for ice sheets, which are conditioned by the altitude of the $0^{\circ} \mathrm{C}$ isotherm, with area under the isotherm increasing non-linearly with rising temperatures. However, a good representation of the current climate over Greenland is no guarantee that the projected changes are reliable. In general the GCMs do not de- pict significant change in the general circulation over Greenland (Belleflamme et al., 2012; Fettweis et al., 2013). Consequently, it may be assumed that if their regional circulation compares well to the reanalyses in the current climate, it should still be valid in the future. But, the mean climate over Greenland, a balance of changes in sea-ice, thermohaline circulation and path of the storm tracks, depends of the ability of the GCM to simulate the climate on the global scale. Thus, the regional climate may be correct due to a compensation of model errors, and therefore, the amplitude of its projected warming could be questionable. Such a possibility is reduced through the use of a model ensemble, here, those available from the CMIP5 database are used.

The surface conditions (except the SST and SIC, which are used as forcing) simulated by the forcing GCM do not considerably vary the results of the RCM but the general atmospheric circulation in the RCM, is fully induced by the GCMbased boundaries forcing. Therefore, GCM atmospheric biases in temperature, humidity and wind with respect to the ERA-Interim at the RCM boundaries, affect results in its integration domain.

With the aim to use them as forcing of a RCM, the fields from the GCMs evaluated here are

- The June, July, and August (JJA) mean temperature at $700 \mathrm{hPa}$. A GCM temperature bias in the free atmosphere is propagated through the RCM boundaries, which induces a similar temperature bias in the RCM. As shown by Fettweis et al. (2013), temporal variability of surface melt in MAR is highly correlated (with a correlation coefficient of $\sim 0.95$ over 1958-2012) with JJA temperature at $700 \mathrm{hPa}$ (T700) over Greenland. 
- The annual mean wind speed at $500 \mathrm{hPa}$. Most of the humidity is advected into the RCM domain at the southern boundary, which is located in the major North Atlantic storm track. The wind speed at the RCM boundaries impacts the moisture advection into the integration domain and hence the precipitation amount simulated by the regional model. It also affects the advection of warm air masses in summer (Fettweis et al., 2011a).

- The annual mean wind direction at $500 \mathrm{hPa}$ that can be gauged by the isohypses of the geopotential height at $500 \mathrm{hPa}$. This last one reflects the main general circulation pattern i.e. an eastward general circulation from the North American continent, deflecting to the northwest over Baffin Bay before reaching the western coast of Greenland, and generating a north-eastward circulation over central Greenland. In southern Greenland, the regional circulation is more influenced by northward circulation patterns. Biases at the RCM boundaries in the direction of the main flows alter the precipitation pattern. As shown by Belleflamme et al. (2012), the agreement (at the daily time scale) between the general circulation from GCMs and reanalyses is seasonally dependant. However, the mean pattern of the general circulation is the same in summer and in winter. That is why, an evaluation at the annual scale is enough here.

The evaluation of the variables listed above is enough to explain most of the differences between MAR forced by the GCMs and MARERA-Interim. Biases in SST and SIC have less impact on the MAR results (Hanna et al., 2009), and the specific humidity in the free atmosphere from GCMs compare generally well with the one from ERA-Interim (not shown here).

The CMIP5 GCMs used here (CanESM2, MIROC5 and NorESM1-M) have been selected among the most suitable GCMs from the CMIP5 database (with 6-h outputs available at the model levels) in respect to their ability to simulate the summer free-atmosphere (at $700 \mathrm{hPa}$ ) temperature and the general circulation over Greenland at $500 \mathrm{hPa}$ (see the Supplement). Our choice has been predominately dictated by the ability of the GCMs to simulate the climate of summer, which is the key season for a correct representation of the GrIS surface melt. In addition, these three GCMs have also been selected by Belleflamme et al. (2012) for their ability to simulate the general circulation over Greenland at a daily time scale over 1960-1990 in respect to the reanalysis version 1 of the National Centers for Environmental Prediction (NCEP) and the National Center for Atmospheric Research (NCAR). However, this does not mean that they perform well at the global scale and hence their future projections may not be reliable. Two RCM simulations using BCC-CSM1-1 and HadGEM2-ES as forcing are also shown to illustrate the role of summer temperature biases in the GCMs on SMB in the RCMs and on its future projections. While the HadGEM2ES general circulation compared well against the reanalyses
(Belleflamme et al., 2012), its atmosphere is $1-2^{\circ} \mathrm{C}$ warmer in summer (1960-2010) than the ECMWF reanalysis, and BCC-CSM1- 1 is $2-3{ }^{\circ} \mathrm{C}$ cooler (see Fig. S7 in the Supplement). Finally, a comparison of the ERA-40 reanalysis and the NCEP-NCAR reanalysis is also performed to evaluate the uncertainties within the reanalyses over Greenland, and compared to the GCMs anomalies with respect to ERA-Interim.

\subsection{Average annual rates and spatial variability of SMB components over 1980-1999}

The SBM describes the integral response of the ice sheet to the climatic forcing. To identify differences in the forcing, we break the SMB down into its components under current climate conditions (1980-1999) (Table 2) and we compare

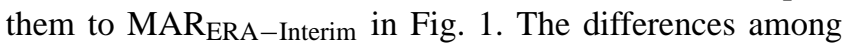
the different forcing models are illustrated in Fig. 2 in respect to ERA-Interim. Figures similar to Fig. 2 but for the 30 CMIP5 GCMs used in Sect. 6.1 are shown in the Supplement (see Fig. S5a, b).

With respect to the MAR $\mathrm{ERA}_{\text {Interim }}$ simulation over 19801999 , results show that

- MARERA-40 simulates less run-off and more precipitation because the ERA-40 atmosphere is a bit colder and drier than ERA-Interim. Part of these differences can be attributed to an improvement of the representation of the GrIS climate in ERA-Interim as compared to ERA-40 (Dee et al., 2011; Screen and Simmonds, 2011). Moreover, these discrepancies (lower

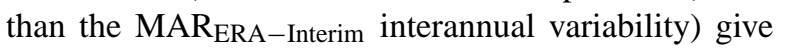
an estimate of the uncertainties made over current climate when MAR is forced by reanalyses. Finally, the comparison of MAR ERA-40 $_{\text {over } 1960-1979 \text { vs }}$ MAR $_{\text {ERA-Interim }}$ over 1980-1999 illustrates the stability of the SMB from 1960-1999 and hence justifies $1980-1999$ as the reference period.

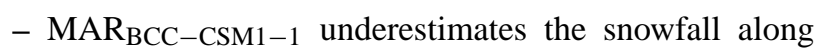
south-east Greenland because BCC-CSM1-1 underestimates the strength and the meridional component of the north-easterly flow over this area. Since the BCC-CSM1-1 atmosphere is statistically significantly colder $\left(2-3^{\circ} \mathrm{C}\right)$ than for ERA-Interim in summer, $\mathrm{MAR}_{\mathrm{BCC}-\mathrm{CSM} 1-1}$ underestimates the water run-off.

- MAR CanESM2 $_{2}$ underestimates the SMB in the northwest of the Greenland ice sheet and overestimates it in the south and along the north-eastern coast. The SMB negative anomalies in the north-west are due to a combination of negative snowfall anomalies and positive water run-off anomalies induced by biases in summer temperature and winter accumulation, as explained by Fettweis et al. (2011c). In addition to its impact on $\mathrm{SMB}$, a low winter snowfall results in an earlier exposure of bare ice during summer melt, and since ice has a 


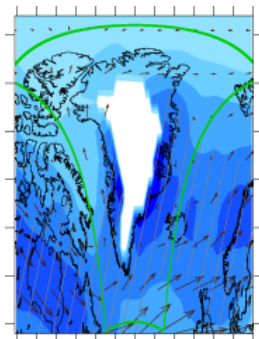

Bias: -2.1

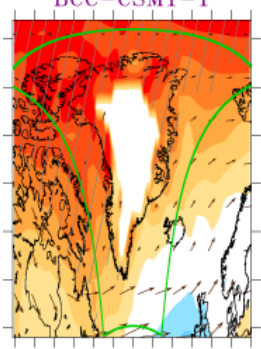

Bias: 1.3

HadCM3-ICE2SEA

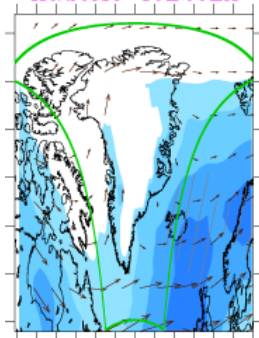

Bias: -1.1
BCC-CSM $1-1$

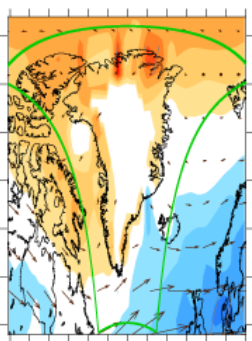

Bias: -0.8

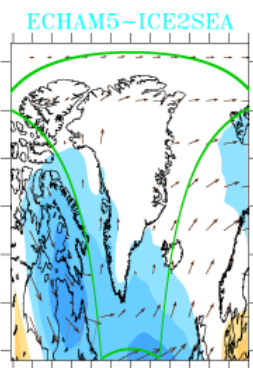

Bias: -0.7

MIROC5

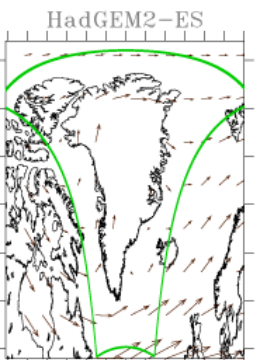

Bias: -0.1

ERA-40-Reanalysis

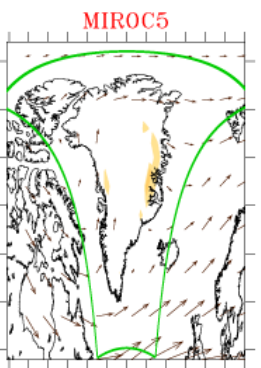

Bias: -0.1

NCEP-NCAR-Reanalysis

anomaly

with respect to $\mathrm{ERA}-\mathrm{Interim}$ over $1980-1999\left({ }^{\circ} \mathrm{C}\right)$

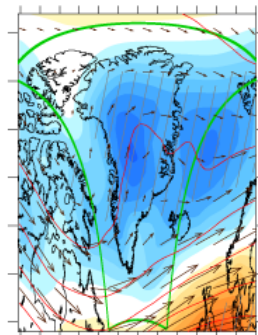

bias: -1.3

BCC-CSM $1-1$

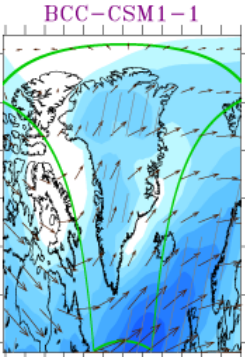

bias: -1.2

HadCM3-ICE2SEA

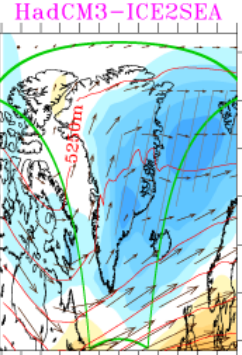

bias: -0.8

NorESM1 - V

Annual $500 \mathrm{hPa}$ wind speed anomaly

with respect to ERA-Interim over $1980-1999(\mathrm{~m} / \mathrm{s})$

Fig. 2. (Left) Mean anomalies of the JJA $700 \mathrm{hPa}$ temperature simulated by the different GCMs used in this study with respect to ERAInterim over 1980-1999. The JJA mean wind vectors (not anomalies) at $700 \mathrm{hPa}$ are also plotted and the mean temperature bias is listed in normalised value. The boundaries of the MAR integration domain are plotted in green and the areas where the anomalies are two times above the 1980-1999 standard deviation of ERA-Interim are hatched in dark grey. Finally, it must be noted that the data sets are shown here by using their native Lat and Long projections. Right panel same as left but for the annual mean wind speed at $500 \mathrm{hPa}$. The annual mean wind vectors at $500 \mathrm{hPa}$ and isohypses of the geopotential height at $500 \mathrm{hPa}$ are also plotted in black and red, respectively.

lower albedo, results in a higher ablation (Mote, 2003; Tedesco et al., 2011). This snowfall negative anomaly is due to an underestimation by CanESM2 of the southwesterly flow impacting the amount of moisture that is advected to this area, while in the south of the ice sheet, the zonal flow is conversely overestimated by CanESM2 enhancing the precipitation amount in MAR. Finally, the pattern of MAR ${ }_{\text {CanESM2 }}$ melt anomalies reflects the pattern of the CanESM2 JJA temperature biases at $700 \mathrm{hPa}$ obtained in the case of ERA-Interim. At the scale of the whole ice sheet, these biases of opposite sign are compensated and MAR $\mathrm{CanESM}_{2}$ simulates annual SMB rates very close to MAR $\mathrm{ERA}_{\mathrm{A}}$ Interim.
- MAR ECHAM5 $_{2}$ and MAR HadCM3 $_{3}$ considerably underestimate the snowfall (mainly in the south) and overestimate the water run-off (mainly along the western and northern coast) because both forcing GCMs are too warm at $700 \mathrm{hPa}$ in summer (mainly HadCM3) and underestimate the strength of the large-scale atmospheric circulation (mainly ECHAM5), gauged here by the wind speed at $500 \mathrm{hPa}$. Similar to MAR CanESM2 $_{2}$ in the north-west of the ice sheet, the accumulation underestimation induces a melt overestimation. Such biases alter the equilibrium line altitude (ELA) that shifted $25-50 \mathrm{~km}$ towards the interior of the ice sheet with respect to MARERA-Interim. This explains why the SMB 
Table 2. Average and standard deviation (gauging the interannual variability) of the annual surface mass balance components simulated by MAR and RACMO2 over 1980-1999. Units are GT yr ${ }^{-1}$ and acronym of each simulation ( $\mathrm{RCM}_{\text {forcings }}$ ) is given in the first column. The surface mass balance (SMB) equation here is SMB = snowfall + rainfall - run-off - water fluxes. The run-off is the part of not refrozen water from both surface melt and rainfall reaching the ocean.

\begin{tabular}{lrrrrrr}
\hline Simulation acronym & SMB & Snowfall & Rainfall & Run-off & $\begin{array}{r}\text { Water } \\
\text { fluxes }\end{array}$ & Meltwater \\
\hline MAR $_{\text {ERA-Interim }}$ & $388 \pm 103$ & $637 \pm 55$ & $25 \pm 4$ & $266 \pm 66$ & $8 \pm 2$ & $449 \pm 91$ \\
\hline MAR $_{\text {ERA-40 }}$ & $447 \pm 106$ & $673 \pm 57$ & $28 \pm 5$ & $247 \pm 68$ & $7 \pm 1$ & $429 \pm 96$ \\
\hline MAR $_{\text {BCC-CSM1-1 }}$ & $433 \pm 92$ & $585 \pm 70$ & $19 \pm 7$ & $161 \pm 49$ & $9 \pm 2$ & $293 \pm 66$ \\
MAR $_{\text {CanESM2 }}$ & $410 \pm 102$ & $635 \pm 51$ & $37 \pm 9$ & $257 \pm 84$ & $5 \pm 2$ & $414 \pm 112$ \\
MAR $_{\text {MIROC5 }}$ & $437 \pm 107$ & $681 \pm 65$ & $26 \pm 6$ & $266 \pm 79$ & $5 \pm 2$ & $445 \pm 99$ \\
MAR $_{\text {NorESM1-M }}$ & $483 \pm 71$ & $691 \pm 58$ & $28 \pm 4$ & $230 \pm 42$ & $6 \pm 1$ & $401 \pm 62$ \\
\hline MAR $_{\text {ECHAM5 }}$ & $223 \pm 88$ & $535 \pm 34$ & $27 \pm 7$ & $323 \pm 80$ & $5 \pm 2$ & $502 \pm 110$ \\
MAR $_{\text {HadCM3 }}$ & $130 \pm 103$ & $422 \pm 49$ & $33 \pm 10$ & $406 \pm 95$ & $8 \pm 2$ & $604 \pm 122$ \\
\hline RACMO2 $_{\text {ECMWF }}$ & $406 \pm 98$ & $683 \pm 60$ & $46 \pm 9$ & $282 \pm 62$ & $41 \pm 4$ & $476 \pm 91$ \\
RACMO2 $_{\text {HadGEM2-ES }}$ & $244 \pm 110$ & $660 \pm 93$ & $54 \pm 16$ & $429 \pm 98$ & $42 \pm 4$ & $657 \pm 131$ \\
\hline
\end{tabular}

biases are the highest along the current ELA (plotted in red in Fig. 1).

- MAR MIROC5 best reproduces the spatial variability

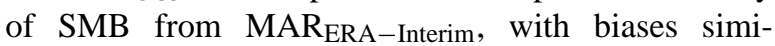
lar to the discrepancies between $M_{\text {ARA-40 }}$ and

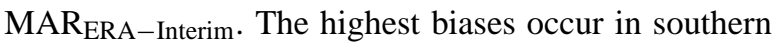
Greenland where the MIROC5 atmosphere is $1^{\circ} \mathrm{C}$ too cold in summer, which weakens the run-off in MAR.

- MAR $_{\text {NorESM1-M }}$ underestimates the run-off because NorESM1-M is $0-1{ }^{\circ} \mathrm{C}$ too cold in summer. The general circulation flow from NorESM1-M is generally too zonal in southern Greenland (as BCC-CSM1-1), which explains why MAR $\mathrm{NorESM1-M}_{\mathrm{M}}$ overestimates the snowfall along the western coast and underestimates it along the eastern coast. At the scale of the whole ice sheet, the melt and snowfall biases add up and explain why MAR $_{\text {NorESM1-M }}$ overestimates the average annual

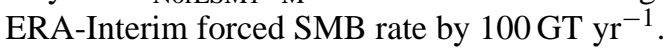

Finally, integrated over the whole ice sheet, the SMB rates from RACMO2 $2_{\mathrm{ECMWF}}$ and MAR $\mathrm{ECMWF}_{\mathrm{W}}$ compare very well over 1960-2011 (see Table 2 and Table S2 in the Supplement). The fact that RACMO2 is run over a different ice sheet mask than MAR and the differences in their physical schemes (Fettweis et al., 2011a) explain the small discrepancies (lower than the interannual variability) between these two RCMs.

As HadGEM2-ES is one of the best CMIP5 GCMs reproducing the general circulation from ERA-Interim (Belleflamme et al., 2012), but because its atmosphere is too warm in summer, RACMO2 ${ }_{\text {HadGEM2-ES simu- }}$ lates successfully the precipitation amount but overestimates the melt by a factor of two with respect to

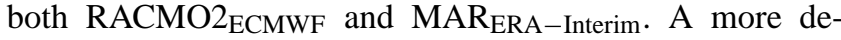
tailed evaluation of RACMO2 ${ }_{\mathrm{HadGEM}}-\mathrm{ES}$ by comparison to RACMO2ERA-Interim is given by van Angelen et al. (2013).

\subsection{Interannual variability over 1980-2012}

An adequate depiction of the model observed interannual variability is an indicator that it will perform well under future simulations. The variability arises due to changes in the storm tracks, the NAO, and the sea ice extent, which may combine to generate decadal variability. However, alignment of these components in GCMs is not likely to be the same as those in the real world. Consequently, we cannot expect temporal coincidence of any observed changes to those in the GCMs, as we are going to see.

As shown by Fettweis et al. (2013), the JJA temperature at $700 \mathrm{hPa}(\mathrm{T} 700)$ taken over an area covering Greenland (20$70^{\circ} \mathrm{W}, 60-85^{\circ} \mathrm{N}$ ) can be used as a proxy of the surface melt variability simulated by MAR over current climate. However, atmospheric temperatures taken at vertical levels (e.g. $700 \mathrm{hPa}$ ) lower than $600 \mathrm{hPa}$ are truncated by the ice sheet topography in most of the CMIP5 models. This explains why T600 simulated by the forcing GCMs is plotted in Fig. 3a, b instead of T700.

From the 1960s to nearly the end of the 1990s, JJA T600 (and then the surface melt) was relatively stable over Greenland (Fettweis et al., 2013). Since summer 1998, ERA-Interim simulates a sharp increase of T600 and then a similar increase of the surface melt is simulated in both MAR $_{\text {ERA-Interim }}$ and RACMO2 ${ }_{\text {ECMWF }}$ (see Fig. 4e). This warming is a combination of the Arctic amplified global warming (Serreze et al., 2009) and changes in the North Atlantic Oscillation (NAO) impacting the general circulation over Greenland (Fettweis et al., 2011a, 2013; Box et al., 

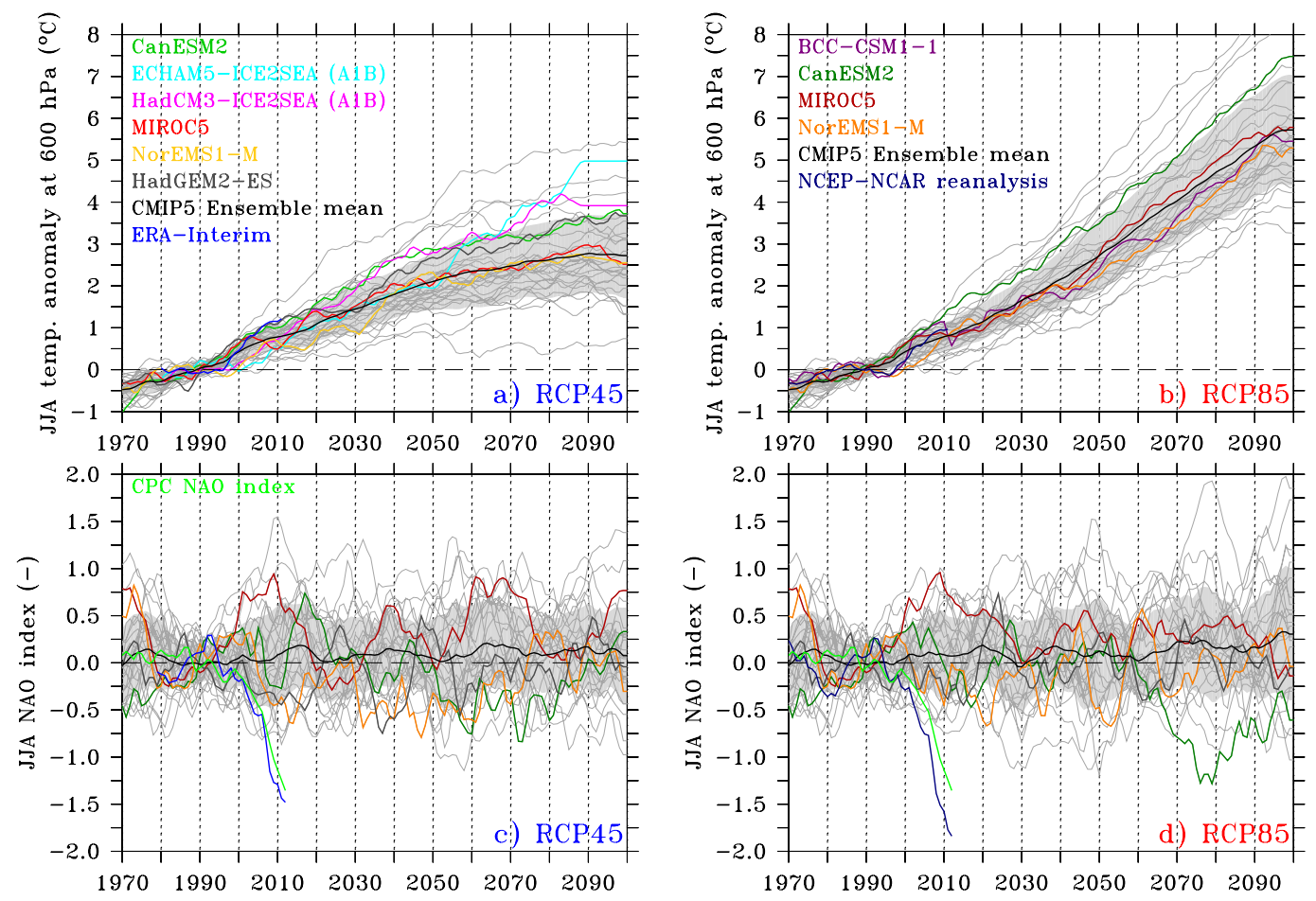

Fig. 3. (a) Anomaly of JJA temperature at $600 \mathrm{hPa}$ (T600) simulated by the reanalyses and the CMIP5 GCMs with respect to 1980-1999 over Greenland for the RCP 4.5 scenario. The anomaly of T600 is taken over an area covering Greenland $\left(20-70^{\circ} \mathrm{W}, 60-85^{\circ} \mathrm{N}\right)$. The ensemble mean as well as the standard deviation of the 30 CMIP5 GCMs are plotted in dark black and in light grey, respectively. Finally, the projections from GCMs used in this study are drawn in colour and a 10-yr running mean is applied for smoothing the curves. (b) Same as (a) but for RCP 8.5. (c) Same as (a) but for a proxy of the JJA NAO index. The NAO index is here estimated as the standardized (over 1980-1999) difference of the JJA air pressure at sea level (PSL) between the Azores $\left(27^{\circ} \mathrm{W}, 39^{\circ} \mathrm{N}\right)$ and Iceland $\left(22^{\circ} \mathrm{W}, 64^{\circ} \mathrm{N}\right)$. The "real" JJA NAO index from the Climate Prediction Center (CPC) (http://www.cpc.ncep.noaa.gov/) is plotted in light green as a comparison. It is also normalised over 1980-1999. (d) Same as (c) but for RCP8.5.

2012; Hanna et al., 2012). This changes in atmospheric circulation (i.e. more frequent anticyclones) have a double impact on the SMB: (i) an increase of surface melt enhanced by more frequent warm air masses advection along the western coast of Greenland by the anticyclones centred over the ice sheet (gauged by negative NAO indexes as shown in Fig. 3c, d); (ii) a decrease of precipitation since the atmosphere is more stable in anticyclonic conditions (see Fig. 4c). Therefore, we observe in both model outputs and satellite data a substantial decrease of GrIS SMB since the end of the 1990s (Rignot et al., 2011). However, a part of this current surface mass loss is due to the North Atlantic Oscillation variability (see Fig. 3c, d) and cannot be considered as a long-term climate change. This explains why all GCM forced simulations fail to reproduce such a decrease of SMB (see Fig. 4a, b) knowing that no CMIP5 GCM projects statistically significant NAO (and then general circulation) changes in future over Greenland (Fig. 3c, d). We refer to Belleflamme et al. (2012) and Fettweis et al. (2013) for more details about this.

Let us start by the analysis of the JJA T600 variability driving the surface melt variability in MAR. Figures 3a and $\mathrm{b}$ show that MIROC5, NorESM1-M and BCC-CSM11 have a temperature sensitivity to GHG increase near the CMIP5 30 GCMs based ensemble mean, while CanESM2 and HadGEM2-ES are amongst the GCMs with the highest sensitives. Nevertheless, only CanESM2 (RCP85) and HadGEM2-ES (RCP45) simulate a warming with an amplitude comparable to ERA-Interim over the period 1980-2012, although this warming starts too early in the GCMs. The other GCMs, and the CMIP5 ensemble mean, depict only half the magnitude of RCM warming. It should be reminded that the current observed acceleration of melt over Greenland is rather a consequence of changes in NAO than of global warming (Fettweis et al., 2013), which explains why most of the GCM forced MAR simulations fail to simulate the current melt increase over the 2000s.

We can also see in Fig. 4 that

- MAR ${ }_{\text {CanESM2 }}$ provides the best simulation of the observed decline in SMB. However, while it simulates the increase in run-off increase, it does not reproduce the MAR $_{\text {ERA-Interim decrease of snowfall in the 2000s. It }}$ is anticipated that snowfall will increase with global 

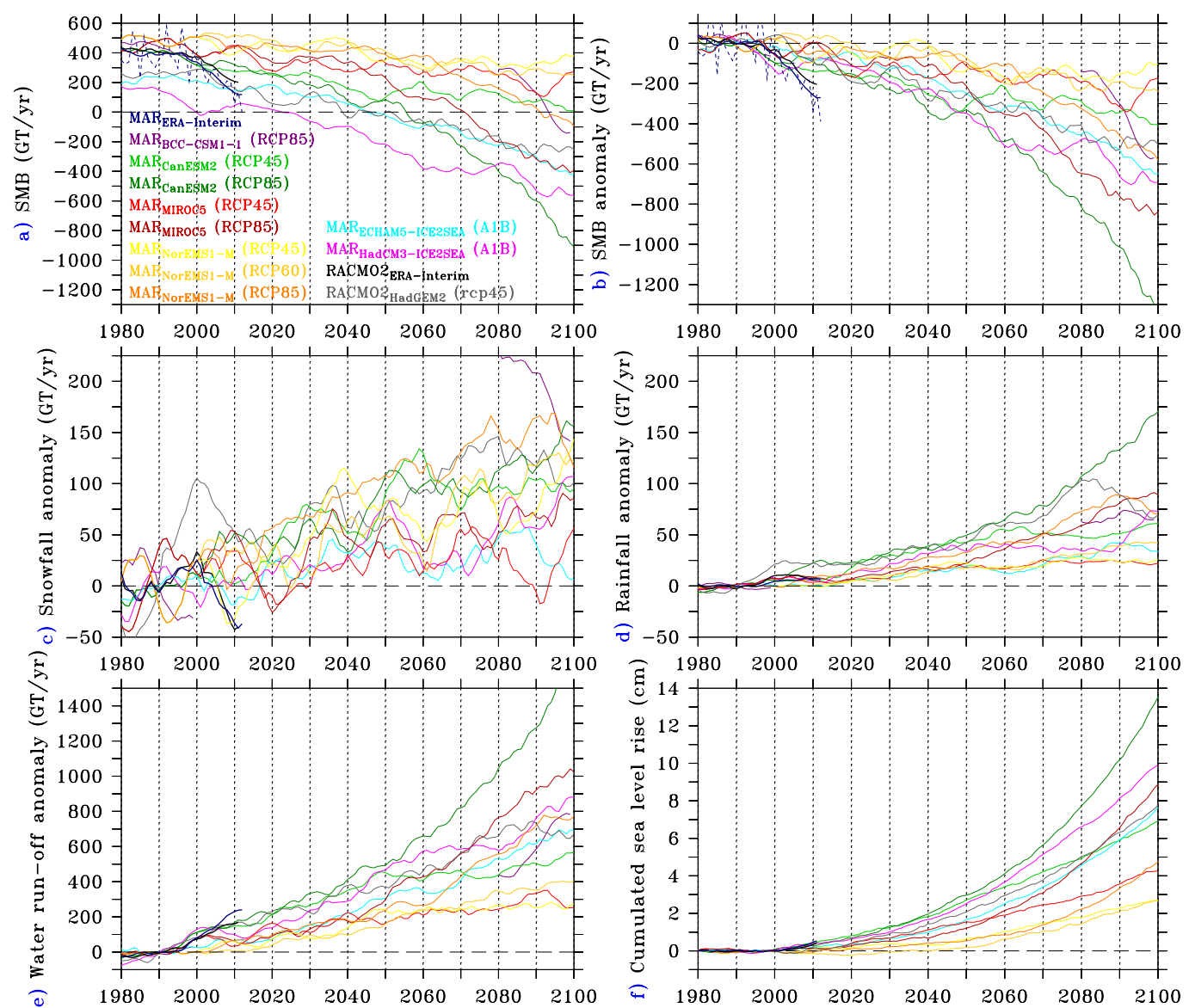

Fig. 4. (a) Time series of the annual total ice sheet SMB (in GT yr ${ }^{-1}$ ) simulated by MAR and RACMO2 forced by the listed GCMs over 1980-1999. (b) Same as (a) but for the SMB anomaly with respect to 1980-1999. (c) Same as (b) but for the snowfall. (d) Same as (b) but for the rainfall. (e) Same as (b) but for the JJA near-surface temperature averaged over the GrIS. (f) The corresponding cumulated sea level rise (in $\mathrm{cm}$ ) from SMB changes. The computations use an ocean area of 361 million $\mathrm{km}^{2}$.

warming, as depicted by the GCMs, and consequently its reduction in ERA-Interim is related to the change in

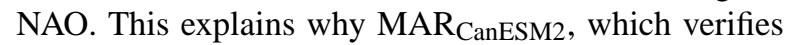
well against MAR ERA-Interim from 1980-2004 (Fig. 4a), underestimates the SMB decrease afterwards.

- MAR ECHAM5 $_{3}$ and MAR HadCM3 $_{3}$ underestimate the SMB through the whole observed period, as well as the current SMB decrease.

- MAR MIROC5 $_{\text {and MAR }}$ NorESM1-M considerably overestimate the SMB after 2000 because they underestimate the current melt positive trend and do not simulate significant changes in snowfall in view of their interannual variability over 1980-1999.

- RACMO2HadGEM2-ES works very well over the 2000s by simulating the melt increase, the snowfall decrease and the RACMO2 $2_{\mathrm{ECMWF}}$ based SMB in absolute value. But, over the period 1980-1999, it simulates a signifi- cant snowfall increase and underestimates the SMB by a factor of two.

\subsection{Conclusions on the evaluation}

As mentioned by Franco et al. (2011) and by Belleflamme et al. (2012), no GCM is able to satisfactorily reproduce all behaviours of the current climate over GrIS, and consequently, no GCM-forced RCM simulation can be selected as the best for making future projections. Indeed, MAR $_{\mathrm{BCC}-\mathrm{CSM} 1-1}$ is too cold. While MAR ${ }_{\mathrm{CanESM} 2}$ well reproduces the total ice sheet SMB and its interannual variability over the period 1980-2012, it underestimates the SMB at the north of the ice sheet and overestimates it at the south. The MAR simulations performed for the ICE2SEA project are affected by several statistically significant biases and are hence likely to be less reliable. The MIROC5, and to a lesser extent NorESM1-M forced simulations, reproduce well the SMB behaviour over the 1980-1999 period but they fail to simulate the SMB decrease observed in the 2000s. Finally, 
RACMO2 HadGEM2-ES compares very well with the ERAInterim forced simulations over 2000-2011 but fails to reproduce the 1980-1999 SMB behaviours.

Since the 2000s, the SMB decrease might be connected to the general circulation natural variability (not simulated by the GCMs) rather than to a long-term change (see Fig. 3c, d), it is better to evaluate the performance of the RCM simulations over the second half of the twentieth century when the climate was stable over Greenland (Fettweis et al., 2013). The period 1980-1999 has been chosen as reference because it is the period covered by all the simulations involved here. However, evaluations over longer periods (e.g. 1960-1999) do not affect the comparison as discussed earlier. According to this, MAR ${ }_{\text {CanESM2 }}$, MAR $_{\text {MIROC5 }}$ and MAR NorESM1-M $_{1}$ are the best performers since most of the biases are statistically insignificant over the 1980-1999 period with respect

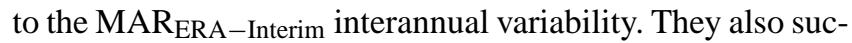
cessfully simulate the seasonal variability of temperature and SMB components, as shown in the Supplement. The remaining simulations are used here to see the impact of biases made over the current climate on their future projections with respect to the three previously cited reference simulations.

\section{Future projections}

\subsection{Trends of the SMB components}

Figure 4 and Table 3 indicate that the projected response of the GrIS SMB to the global warming is highly dependent on the GCM and scenario used for forcing MAR. While all simulations agree in projecting an increase of snowfall and rainfall between +25 and $+150 \mathrm{GT} \mathrm{yr}^{-1}$ by 2100 , the modelled changes in the water run-off vary between +200 and $+1600 \mathrm{GT} \mathrm{yr}^{-1}$ by 2100 , with respect to the $1980-1999$ mean. For the same RCP scenario, there is up to a factor of two between the melt increase simulated by MAR ${ }_{\text {CanESM2 }}$

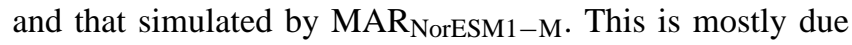
to the fact that there are several degrees of difference between the JJA T600 warming projected by CanESM2 and by NorESM1-M (see Fig. 3). Moreover, it must be noted that RACMO2 ${ }_{\text {HadGEM2-ES }}$ (RCP45) projects SMB decrease by 2100 close to $\mathrm{MAR}_{\text {NorESM1-M }}$ (RCP85), although there is a factor of two between the $\mathrm{CO}_{2}$ concentrations by 2100 between both simulations and future projections for the ICE2SEA project using the SRES A1B scenario (equivalent to the RCP60 scenario) are rather situated in the lower-range future projections for the RCP85 scenario. This is due to the GCM's sensitivity to a GHG concentration increase and to a melt overestimation over current climate, which amplifies the future melt acceleration, as discussed in Sect. 5.

At this stage, we can only conclude that, for all models and all scenarios presented here, the mass gain due to increased snowfall is unable to compensate for the mass losses due to the increased run-off. This implies that the GrIS is projected to considerably lose mass from its surface and to contribute to the sea level rise (Fig. 4f), independently of the impact of increased run-off changes in the ice dynamics.

\subsection{Spatial changes}

All the simulations project a SMB increase of $\sim 100$ $200 \mathrm{~mm} \mathrm{WE} \mathrm{yr}^{-1}$ in the current accumulation zone and a significant SMB decrease of $\sim 1000-3000 \mathrm{~mm} \mathrm{WE} \mathrm{yr}^{-1}$ in the current ablation zone (see Fig. 5) for the period 2080-2099. The thinning rate of the ice sheet along its border and the shift of the ELA towards the centre of the ice sheet depend on the JJA warming amplitude shown in Fig. 5. The highest melt increase occurs at the north of the ice sheet because of the enhanced warming induced by the disappearance of the sea ice cover in the Arctic Ocean (Mernild et al., 2010; Franco et al., 2011). This decrease in the sea ice cover, apart from enhancing the atmospheric warming, also increases the water evaporation and therefore, explains why most of the simulations project a snowfall increase along the eastern margin. This snowfall increase does not come from changes in the general circulation (Belleflamme et al., 2012). A thickening of the ice sheet is also projected near South-Dome (where the maximum of precipitation currently occurs). But, according to MAR ${ }_{\text {CanESM2 }}$ (RCP85), if the warming is too high, the snowfall increase is weakened because most of the precipitation falls as rainfall in summer and the mass gained by heavier snowfall become not enough for compensating the mass loss due to the run-off increase. Finally, heavier snowfall could also occur in the north-east of the ice sheet but it is

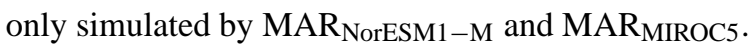

From Fig. 5, we also observe that the JJA near-surface temperature (TAS) increase is not uniformly distributed over the ice sheet. Along the ice sheet margins, the current surface temperature (TS) is already close to $0{ }^{\circ} \mathrm{C}$ in JJA. Since the melting snow/ice TS is limited to the freezing point, this dampens the TAS increase. In the north of the ice sheet and along the eastern coast, the TAS increase over tundra is generally higher over the neighbouring ice sheet. It is true that these pixels are the most affected by the disappearance of the sea ice cover in summer, but these areas are currently covered by snow during a part of summer, and with rising temperature, they could become snow free during most of the summer time and therefore a positive albedo feedback should also occur in these areas. Such effect is not as strong in the south-western tundra area because this area is already snow free during summer in present-day climate.

\section{Sensitivity of the SMB components to rising temperatures}

In the previous section, we have highlighted the existence of a large range in the MAR-based SMB projections induced by the different sensitivities of the GCMs for the same GHG 
Table 3. Anomalies of SMB, snowfall, meltwater run-off (i.e. water run-off minus rainfall) in 2080-2099 with respect to 1980-1999 as well as the cumulated sea level rise in 2100 resulting from SMB anomalies over 2000-2100 simulated by the RCMs as well as by the CMIP5 GCMs using Eq. (1).

\begin{tabular}{|c|c|c|c|c|}
\hline Simulation acronym & $\begin{array}{r}\text { SMB } \\
\left(\mathrm{GT} \mathrm{yr}^{-1}\right)\end{array}$ & Snowfall & $\begin{array}{r}\text { Meltwater } \\
\text { run-off }\end{array}$ & $\begin{array}{r}\text { SLR in } \\
2100(\mathrm{~cm})\end{array}$ \\
\hline MAR $_{\text {NorESM1-M }}(\mathrm{RCP} 26)$ & $-124 \pm 100$ & $+66 \pm 49$ & $+192 \pm 76$ & 2.2 \\
\hline MAR $_{\text {CanESM2 }}(\mathrm{RCP} 45)$ & $-351 \pm 140$ & $+92 \pm 59$ & $+448 \pm 110$ & 6.8 \\
\hline MAR $_{\text {MIROC5 }}$ (RCP45) & $-240 \pm 159$ & $+18 \pm 66$ & $+283 \pm 113$ & 4.2 \\
\hline MAR $_{\text {NorESM1-M }}(\mathrm{RCP} 45)$ & $-160 \pm 113$ & $+81 \pm 69$ & $+243 \pm 89$ & 2.7 \\
\hline RACMO2 ${ }_{\text {HadGEM2-ES }}(\mathrm{RCP} 45)$ & $-476 \pm 184$ & $+122 \pm 57$ & $+686 \pm 181$ & 7.6 \\
\hline CanESM2 (RCP45) & $-306 \pm 118$ & $+106 \pm 58$ & $+411 \pm 89$ & 5.5 \\
\hline MIROC5 (RCP45) & $-279 \pm 88$ & $+13 \pm 59$ & $+292 \pm 54$ & 4.8 \\
\hline NorESM1-M (RCP45) & $-193 \pm 64$ & $+85 \pm 65$ & $+278 \pm 60$ & 2.9 \\
\hline Ensemble mean (RCP45) & $-242 \pm 129$ & $+56 \pm 38$ & $+298 \pm 139$ & $4.4 \pm 2.2$ \\
\hline MAR $_{\text {ECHAM5 }}(\mathrm{A} 1 \mathrm{~B})$ & $-506 \pm 149$ & $+52 \pm 81$ & $+576 \pm 143$ & 7.4 \\
\hline $\mathrm{MAR}_{\mathrm{HadCM} 3}(\mathrm{~A} 1 \mathrm{~B})$ & $-589 \pm 191$ & $+81 \pm 51$ & $+676 \pm 183$ & 9.8 \\
\hline MAR $_{\text {NorESM1-M }}(\mathrm{RCP} 60)$ & $-229 \pm 120$ & $+105 \pm 66$ & $+338 \pm 81$ & 2.7 \\
\hline MAR $_{\mathrm{BCC}-\mathrm{CSM} 1-1}$ (RCP85) & $-324 \pm 224$ & $+196 \pm 66$ & $+592 \pm 194$ & - \\
\hline MAR $_{\text {CanESM2 }}(\mathrm{RCP} 85)$ & $-1014 \pm 251$ & $+129 \pm 62$ & $+1158 \pm 241$ & 13.1 \\
\hline MAR $_{\text {MIROC5 }}$ (RCP85) & $-742 \pm 217$ & $+68 \pm 54$ & $+821 \pm 202$ & 8.8 \\
\hline MAR $_{\text {NorESM1-M }}(\mathrm{RCP} 85)$ & $-436 \pm 199$ & $+155 \pm 84$ & $+599 \pm 170$ & 4.6 \\
\hline CanESM2 (RCP85) & $-1050 \pm 245$ & $+130 \pm 45$ & $+1180 \pm 235$ & 12.8 \\
\hline MIROC5 (RCP85) & $-748 \pm 169$ & $+64 \pm 45$ & $+813 \pm 157$ & 9.3 \\
\hline NorESM1-M (RCP85) & $-546 \pm 201$ & $+135 \pm 71$ & $+681 \pm 191$ & 5.9 \\
\hline Ensemble mean (RCP85) & $-710 \pm 349$ & $+94 \pm 42$ & $+804 \pm 346$ & $9.0 \pm 4.3$ \\
\hline
\end{tabular}

scenario. Hence, it is complicated to compare future projections forced by different GCMs and scenarios, because they result from different TAS increases. In addition, in view of the sensitivity of the GCMs used as forcings in our projections, using only three GCMs is not enough for evaluating the uncertainties from GCMs in our simulations.

Therefore, we perform in this section an analysis of the sensitivity of the SMB components to temperature anomalies (regardless of when such temperature anomalies are projected to occur). The different projections become more consistent in this case and show the importance of well simulating the current climate. In addition, with the aim of estimating GrIS SMB changes from GCM outputs only, we are going to select some GCM variables that best explain the changes (integrated at the scale of the whole ice sheet) in the SMB components simulated by the forced RCM. Since the multimodel mean is often considered by the IPCC as the best estimate of the simulated climate response to both natural and anthropogenic forcings, it is interesting to evaluate which MAR simulations presented here are the closest to the CMIP5 ensemble mean. It should, however, remind us that the CMIP5 ensemble mean underestimates the current temperature increase over GrIS. In addition, this allows us to estimate the uncertainties in our simulations, coming from the GCM's sensitivity, in a similar RCP scenario.

\subsection{Precipitation}

In a warmer climate, there is more evaporation above the ocean and the atmosphere can contain more water vapour. This leads to higher moisture transport inland and, consequently, heavier precipitation as shown in Figs. 6a and b. In agreement with Gregory and Huybrechts (2006), total precipitation (snowfall + rainfall) increases with a relative precipitation change estimated to be $5 \% \mathrm{~K}^{-1}$, as plotted in black in Fig. 6b. A mean value of $700 \mathrm{GT} \mathrm{yr}^{-1}$ over current climate is used for plotting the $5 \% \mathrm{~K}^{-1}$ relative precipitation change.

The sensitivity of the snowfall amount to a warming climate is more simulation dependent than rainfall, which increases almost linearly with the GrIS TAS anomaly taken over JJA (when most of the rainfall events occur). Rainfall increases mainly because a part of the precipitation currently falling in solid phase is projected to fall in liquid phase and this effect is directly temperature dependent. This can be seen in Fig. 6c where for summer temperature anomalies higher than $3{ }^{\circ} \mathrm{C}$, the snowfall increase is dampened by the conversion of snowfall to rainfall. It must be noted that the rainfall increase does not contribute significantly to the SMB changes because this occurs mostly over bare ice or saturated surfaces where liquid water runs off in both MAR and RACMO2 models. That is why, only runoff of meltwater (called meltwater run-off hereafter) will be 

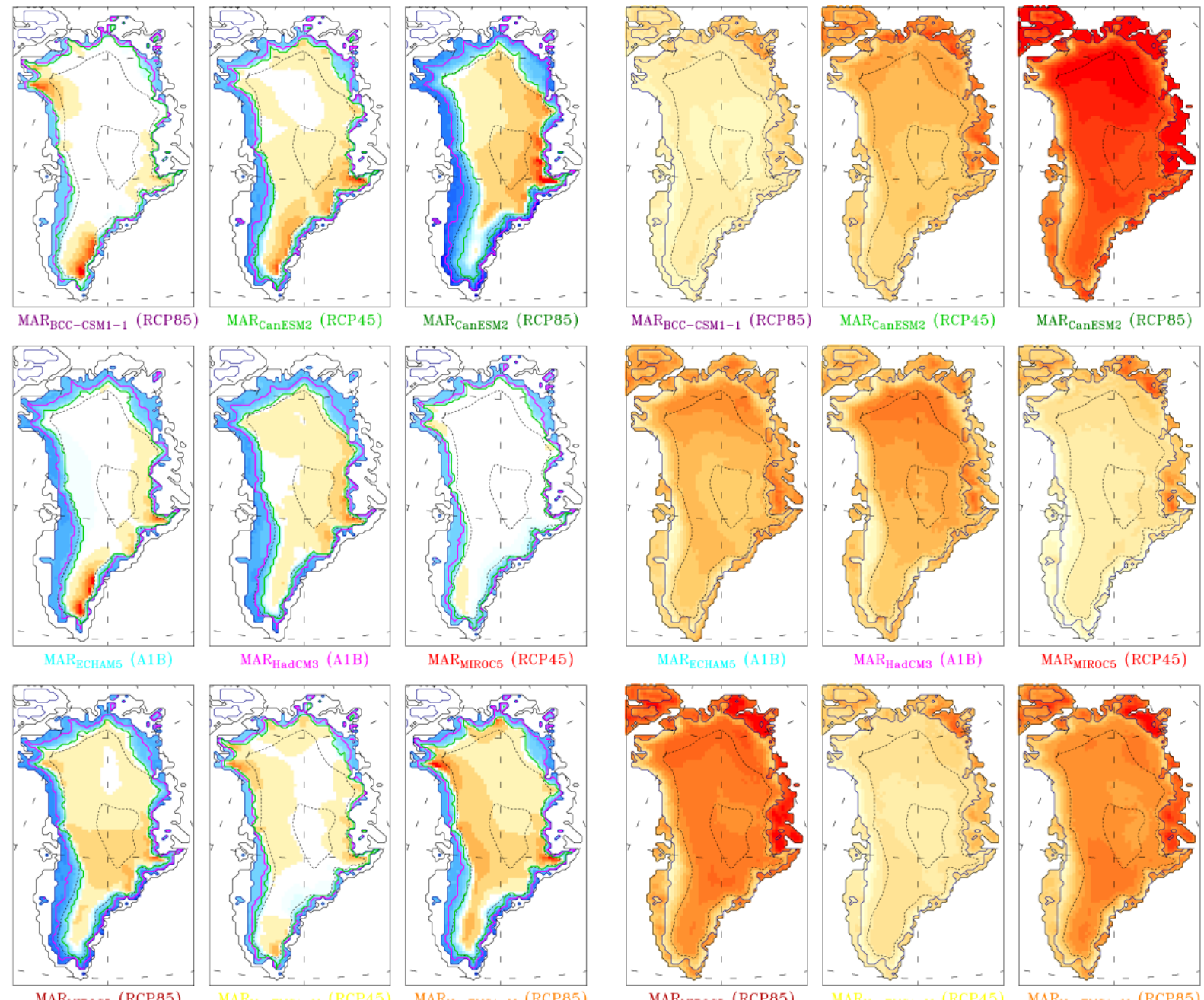

$\mathrm{MAR}_{\mathrm{MTROC}}$ (RCP85)

MAR NorEMS1-M $_{2}$ RCP85)

2080-2099 annual total SMB anomaly (mmWE/yr)
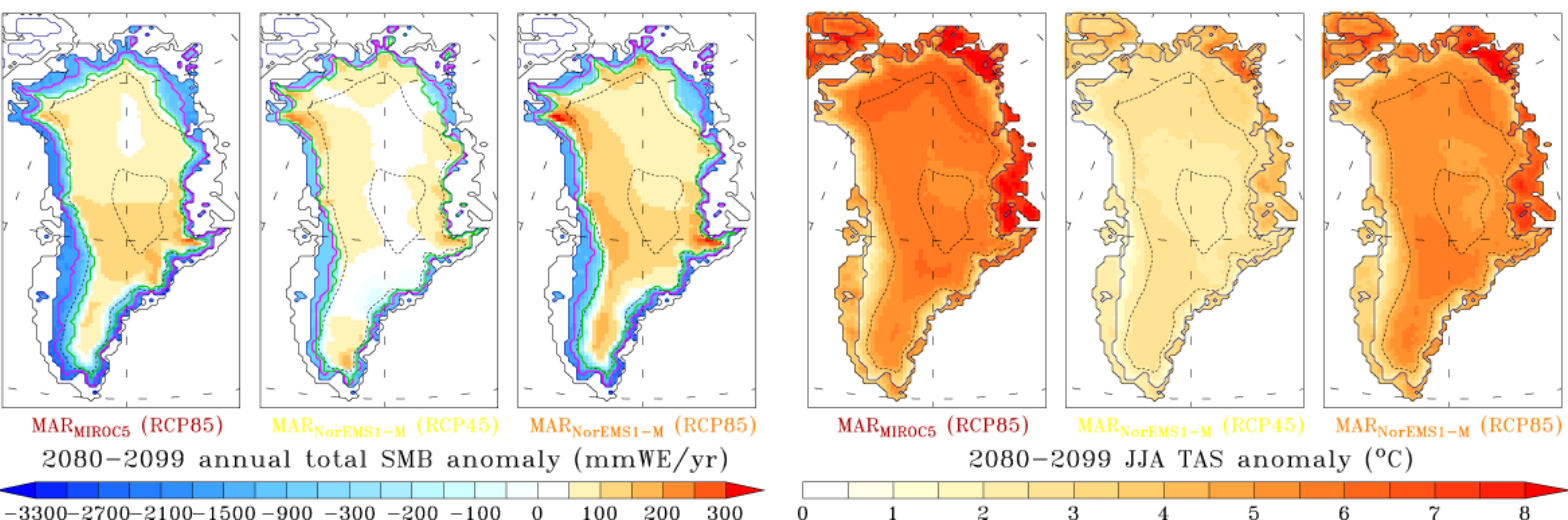

Fig. 5. Anomalies of the mean annual SMB over 2080-2099 with respect to 1980-1999. Units are mm WE yr ${ }^{-1}$. Finally, the ELA over 1980-1999 (resp. 2080-2099) is plotted in mauve (resp. green).

discussed in the next section. However, rainfall instead of snowfall over bare ice areas disallows short time albedo risings (Box et al., 2012) and then contributes to accelerate the melt over bare ice.

We can also see in Fig. 6c that MAR ERA-Interim shows a more significant JJA snowfall decrease with rising temperatures than the GCM forced MAR simulations, as a result of the observed increase of anticyclonic conditions in summer. These circulation changes induced drier conditions over the ice sheet (Box et al., 2012; Fettweis et al., 2013), whereas the warmings simulated by the GCMs are not associated with circulation changes over Greenland.

Conversely to rainfall, the snowfall increase is not only driven by the rising temperatures because to the snowfall increase, in response of higher TAS, the snowfall interannual variability is superposed $\left(\sim 50-70 \mathrm{GT} \mathrm{yr}^{-1}\right.$ over current cli- mate), which is of the same order of magnitude as the snowfall increase. This explains the larger range in the snowfall increase vs rising TAS.

Since the snowfall interannual variability is driven by the variability in the GCM-based general circulation (Schuenemann and Cassano, 2010), the RCM-based annual snowfall anomaly can then be estimated using the annual snowfall anomaly from the GCM. This precipitation estimation will be used in the next section to estimate GrIS SMB changes from GCMs outputs. It is obvious that precipitation changes simulated by RCMs and GCMs can be very different locally but at the scale of the whole ice sheet, they compare relatively well, as shown in Fig. 6d. To estimate the snowfall over GrIS from GCMs, we select the GCM pixels located over the region covering Greenland $\left(20-70^{\circ} \mathrm{W}\right.$ and $\left.60-85^{\circ} \mathrm{N}\right)$ and having an altitude of at least $1000 \mathrm{~m}$ a.s.l using the orography 

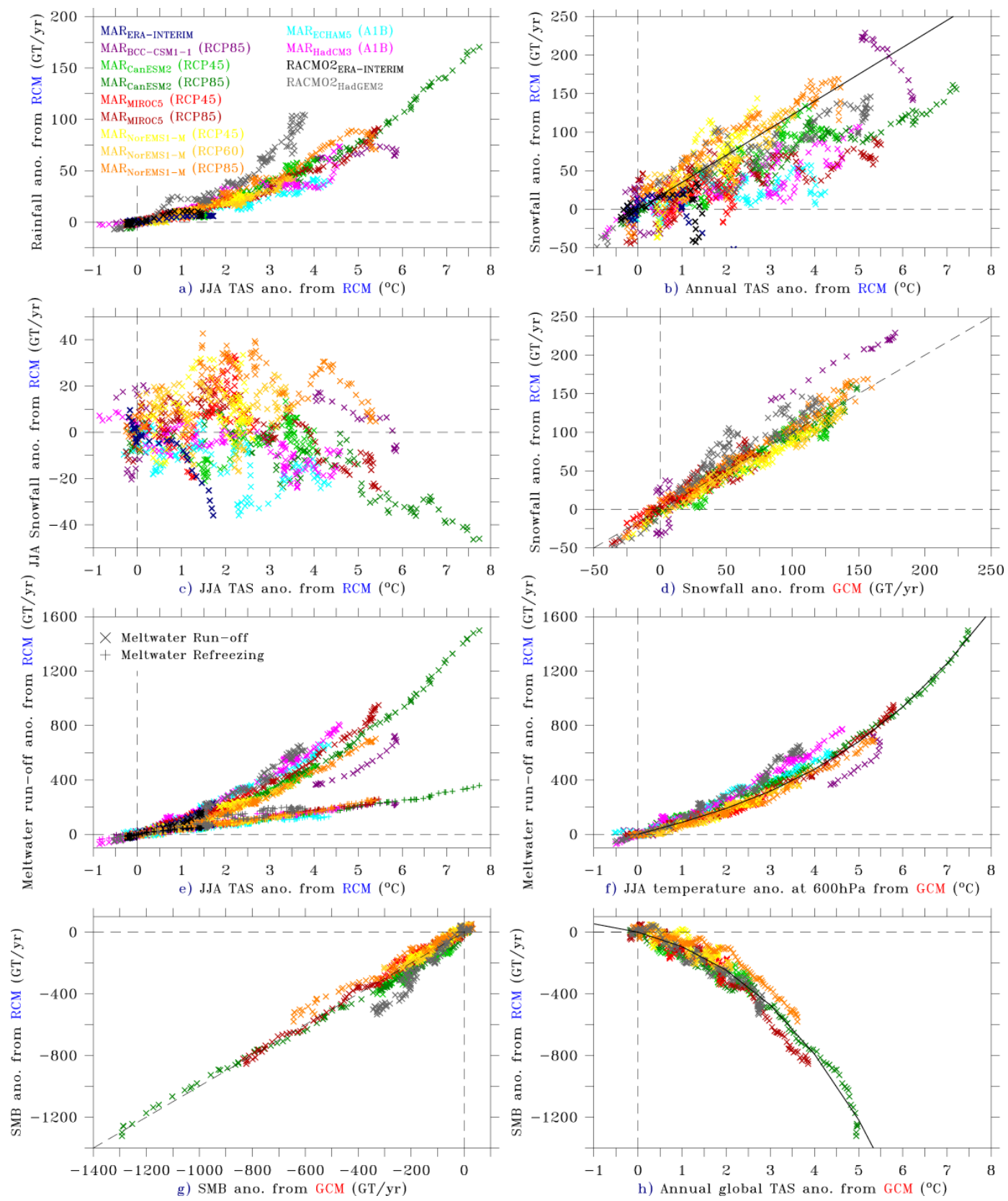

Fig. 6. (a) Anomalies of the annual total GrIS rainfall (in GT yr ${ }^{-1}$ ) versus the JJA GrIS TAS anomaly (in ${ }^{\circ} \mathrm{C}$ ) simulated by the RCMs over 1980-2100. The anomalies are given with respect to 1980-1999 and a 10-yr running mean has been applied to the time series before making the scatter plot. (b) Same as (a) but for annual total snowfall vs annual GrIS TAS. (c) Same as (a) but for annual total meltwater run-off vs JJA GrIS TAS. (d) Same as (a) for annual total meltwater run-off vs the JJAS (from June to September) temperature anomaly from GCM taken at $600 \mathrm{hPa}$ over the area $\left(20-70^{\circ} \mathrm{W}, 60-85^{\circ} \mathrm{N}\right)$. (e) Same as (a) but for the annual total SMB from RCMs vs the estimated one from GCMs using Eq. (1). (f) Same as (a) but for the annual total SMB from RCMs vs the annual global TAS from GCMs.

(variable OROG in the CMIP5 database) of each GCM. Since snowfall (variable PRSN) is given in $\mathrm{kg} \mathrm{m}^{2} \mathrm{~s}^{-1}$ in the CMIP5 database, we convert these values to $\mathrm{GT}^{-1}$ by using a constant factor $365 \times 24 \times 600 \times k$, where $k$ is a parameter fixed to 1.6, to achieve the best comparison of the GCM-based versus RCM-based snowfall changes.

\subsection{Meltwater run-off and refreezing}

As shown in Fig. 6e, the GrIS meltwater run-off increases not linearly with rising JJA TAS. While meltwater anomalies can be approximated by a linear function of TAS anomalies over current climate (Box et al., 2004; Fettweis et al., 2008), this linear relationship is not conserved for warmers 
climates (i.e. TAS anomaly higher than $2-3^{\circ} \mathrm{C}$ ) as a result of the surface albedo positive feedback mechanism associated to the extension of the summer ablation zone (Franco et al., 2013). In addition to decreasing the surface albedo, the bare ice areas extension prevents efficient percolation and subsequent refreezing at the beginning of winter. This explains why the meltwater refreezing increases slower with rising JJA TAS than meltwater run-off, and therefore, the total refreezing capacity of the ice sheet is projected to decrease (van Angelen et al., 2013).

Regarding the sensitivity of meltwater run-off to JJA TAS increase, it depends on the ability of the GCM-forced MAR to successfully represent the current run-off rate simulated by MAR $R_{\text {ERA-Interim }}$, since the melt does not increase linearly with warming climates. This means that the simulations that overestimate meltwater production over current climate (e.g. the MAR projections made for ICE2SEA) project a larger sensitivity than $\mathrm{MAR}_{\mathrm{BCC}-\mathrm{CSM} 1-1}$, which is too cold over current climate. The three reference simulations agree for giving intermediate sensitivities. However, it must be noted that the run-off sensitivity is also affected by the projected changes in snowfall (Fig. 6b-c), which varies the surface albedo and then the melt in summer (Mote, 2003). Finally, although Fig. 6e shows that the meltwater run-off anomalies vs JJA TAS anomalies depend upon the ability of simulating the current climate, it must be noted that the discrepancies between these projections are lower than the projected changes.

With the aim of evaluating GrIS SMB from GCM outputs, the RCM simulated meltwater run-off anomalies at the scale of the whole ice sheet, which can be estimated using the JJA T600 anomaly from GCM as shown in Fig. 6f. The temperatures at $600 \mathrm{hPa}$ have been chosen to be independent of the surface scheme used in the GCMs (see the Supplement) and because the JJA T600 explains well the melt variability over current climate (as discussed earlier). For the three reference future projections, the MAR-based meltwater runoff sensitivity to an equal JJA GCM-based T600 is almost

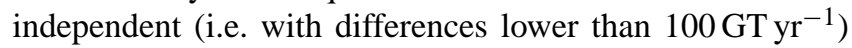
of the GCM used as forcing. Such an independence in the used forcing occurs because no change in general circulation is projected by these GCMs and a 10-yr running mean is applied here. Therefore, the melt increase is only driven by the warming of the free atmosphere over Greenland independently of the used GCM.

\subsection{Approximation of the SMB changes using GCMs results}

Boosted by the good comparison of RCM vs. GCM in Fig. 6f, we approximate the MAR-based GrIS SMB anomalies using the following equation

$$
\begin{aligned}
\Delta \mathrm{SMB} & \simeq \Delta \mathrm{SF}-84.2 \cdot \Delta T 600_{\mathrm{JJA}} \\
& -2.4 \cdot\left(\Delta T 600_{\mathrm{JJA}}\right)^{2}-1.6 \cdot\left(\Delta T 600_{\mathrm{JJA}}\right)^{3},
\end{aligned}
$$

where $\Delta \mathrm{SF}$ is the snowfall anomaly simulated by GCMs over GrIS (see Sect. 5.1), and where the third order polynomial equation in the GCM-based JJA T600 anomaly is plotted in black in Fig. 6f. The coefficients of this polynomial equation have been chosen to best fit the three reference simulations.

The ability of approximating the RCM-based GrIS SMB using Eq. (1) is shown in Fig. 6g. The RMSE (root mean square error) between the GCM-derived SMB and the MARsimulated one for the three reference future projections is 87 (resp. 35) $\mathrm{GT} \mathrm{yr}^{-1}$ while the correlation coefficient is 0.89 (resp. 0.98) without (resp. after) applying a 10-yr running mean to the time series. Such agreement gives us some confidence in our GCM-based SMB estimates using Eq. (1). More detailed statistics can be found in Table S3 in the Supplement. Finally, it should be reminded that Eq. (1) can only be used to estimate annual SMB anomalies at the scale of the whole ice sheet and does not work for estimating SMB anomalies at finer spatial and temporal scales.

Finally, as shown in Fig. 6f, the GrIS SMB anomalies simulated by MAR can also be approximated by:

$$
\begin{aligned}
\Delta \mathrm{SMB} & \simeq-71.5 \cdot \Delta \mathrm{TAS}_{\text {global }} \\
& -20.4 \cdot\left(\Delta \mathrm{TAS}_{\text {global }}\right)^{2}-2.8 \cdot\left(\Delta \mathrm{TAS}_{\text {global }}\right)^{3},
\end{aligned}
$$

where TAS (TAS global $_{\text {) }}$ is the annual global TAS anomaly in respect to 1980-1999 (Eq. 2 is plotted in black in Fig. 6f). By comparison with Eq. (1) based SMB estimations, the RMSE between the global TAS derived SMB and the MARsimulated one for the three reference future projections is 137 (resp. 60) $\mathrm{GT} \mathrm{yr}^{-1}$ while the correlation coefficient is 0.67 (resp. 0.90) without (resp. after) applying a 10-yr running mean to the time series.

\section{Discussion}

\subsection{Future SMB changes based on CMIP5 multimodel mean}

According to Fig. 7, the increase of snowfall that is projected by MAR MIROC5 $_{\text {(resp. MAR }}$ CanESM2 $_{2}$ and MAR NorESM1-M) is below (resp. above) the CMIP5 multimodel mean based on $30 \mathrm{GCMs}$ (noted hereafter $30 \mathrm{ENS}_{\mathrm{CMIP} 5}$ ). Regarding the projected SMB decreases, MAR MIROC5 $_{\text {is }}$ the closest to 30ENS ${ }_{\text {CMIP5 }}$ while MAR CanESM2 $_{\text {(resp. MAR }}$ NorESM1-M $_{\text {) }}$ overestimates (resp. underestimates) the SMB changes projected by $30 \mathrm{ENS}_{\mathrm{CMIP}}$. Therefore, notably in the aim of forcing ice sheet models in the framework of the ICE2SEA

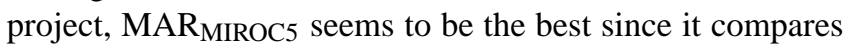
very well over 1980-1999 with MAR ERA-Interim $_{\text {and }}$ its future projections are in mid-range because they are close to $30 \mathrm{ENS}_{\mathrm{CMIP} 5}$.

In $2100,30 \mathrm{ENS}_{\mathrm{CMIP5}}$ projects a SLR due to changes in GrIS SMB to be $\sim+4.4 \pm 2.2 \mathrm{~cm}$ and $\sim+9.0 \pm 4.3 \mathrm{~cm}$ for RCP 4.5 and RCP 8.5 experiments, respectively. These projections are in the range of previous estimates (IPCC, 2007). 

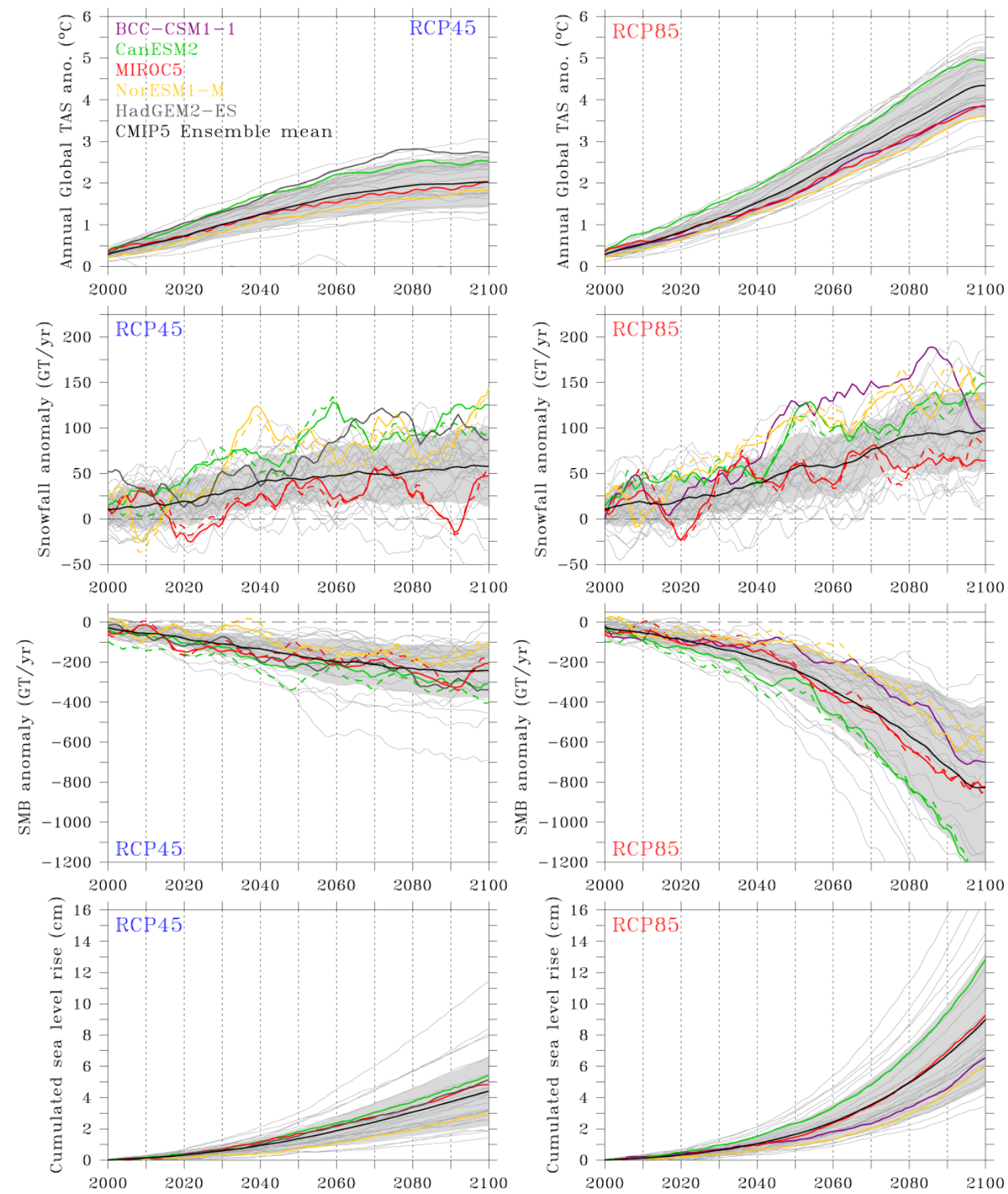

Fig. 7. Same as Fig. 3 but for the annual global TAS (in ${ }^{\circ} \mathrm{C}$ ), GrIS snowfall and SMB anomaly in $\mathrm{GT} \mathrm{yr}^{-1}$ according to Eq. (1) as well as the corresponding sea level rise in $\mathrm{cm}$. The dashed coloured lines plot the time series from MAR forced by the corresponding GCMs.

The TAS' increased threshold for having a negative SMB is often considered as the maximum warming before irreversible ice sheet topography changes (Gregory and Huybrechts, 2006) and is therefore often studied (Rae et al., 2012; Robinson et al., 2012). However, to estimate when the SMB integrated over the whole ice sheet could become negative in our simulations, using absolute values of SMB (Fig. 4a) instead of relative values (Fig. 4b) could be questionable because for simulations underestimating the current SMB (e.g. RACMO2 ${ }_{\text {HadGEM2-ES }}, M$ RR $_{\text {HadCM3 }}$ ) a negative
SMB will occur earlier. That is why, it is more appropriate to use a SMB anomaly $<-400 \mathrm{GT} \mathrm{yr}^{-1}$ as a threshold since the SMB over 1980-1999 is simulated by MAR and RACMO2 to be $\sim 400 \mathrm{GT} \mathrm{yr}^{-1}$ (Vernon et al., 2012). In this case, Eq. (1) can be used and 30ENS suggests that such SMB rates are projected to occur beyond this century according to RCP45 but should occur around 2070 according to the RCP85 scenario. Equation (2) shows that a global TAS anomaly of $\sim+3{ }^{\circ} \mathrm{C}$ is needed for having a SMB anomaly 

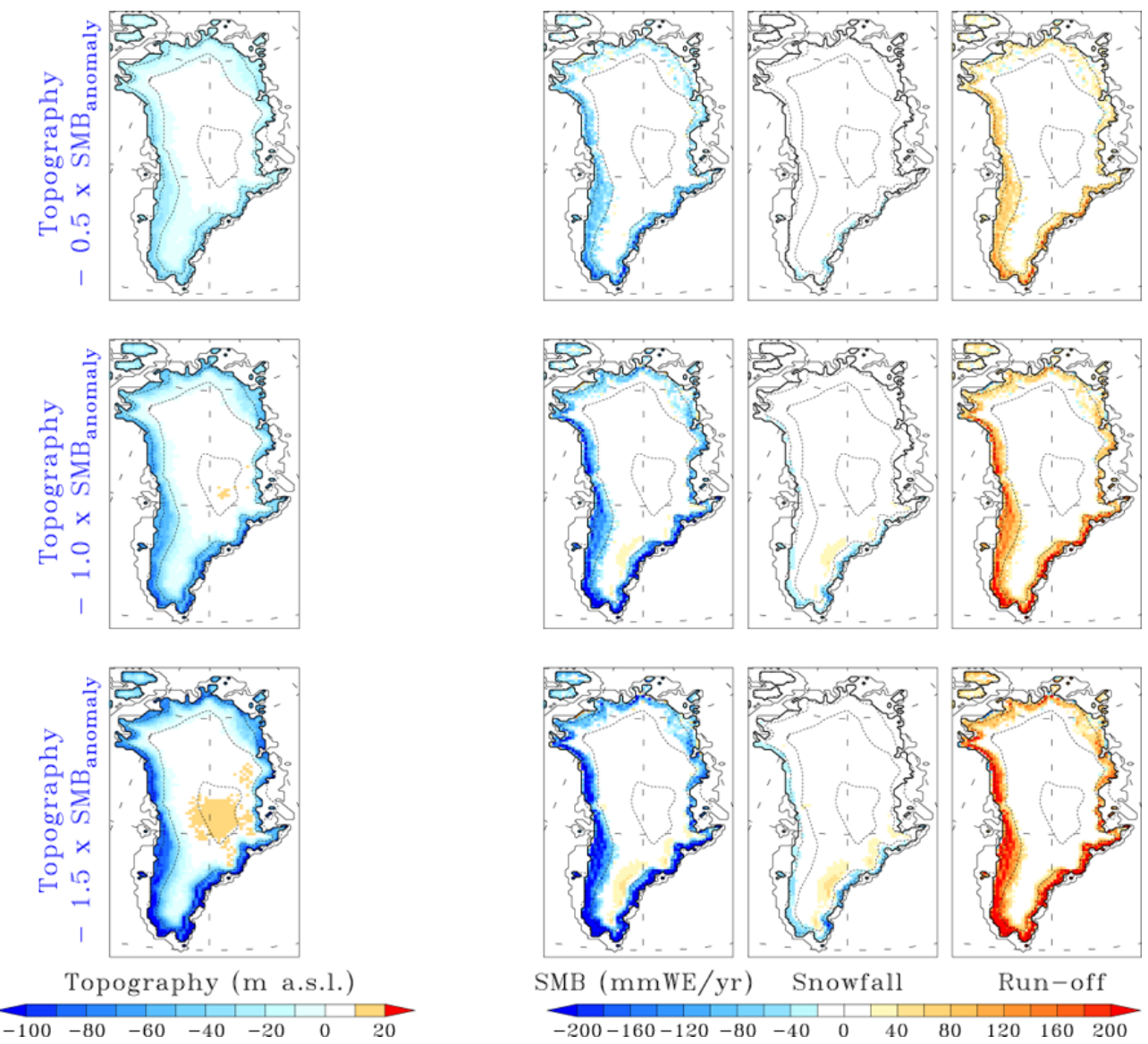

Fig. 8. (Left) Difference of surface elevation (in $\mathrm{m}$ a.s.l.) between the control run and the three sensitivity experiments. The ice sheet topography used in the sensitivity experiments is the control run topography plus $0.5,1.0$ and 1.5 times the cumulated surface height anomaly from 2000-2080 SMB changes simulated by MAR MIROC5 (RCP85) using a fixed topography. (Right) Difference over 2080-2099 of the mean annual SMB, run-off and snowfall in $\mathrm{mmWE} / \mathrm{yr}$ between the three sensitivity experiments and the control run.

$<-400 \mathrm{GT} \mathrm{yr}^{-1}$, which is in full agreement with the estimations from Robinson et al. (2012).

\subsection{Uncertainties in our SMB changes estimation}

\subsubsection{From RCMs}

According to Vernon et al. (2012), the uncertainty in the current GrIS SMB modelled by the RCMs is $\sim 50 \mathrm{GT} \mathrm{yr}^{-1}$ i.e. $\sim 10 \%$ of the current GrIS SMB. For warmer climates, this uncertainty could be higher knowing that the response of the SMB to rising temperatures is not linear. However, Fig. 6e suggests that the sensitivity of the melt projected by MAR and RACMO2 is similar if we compare RACMO2 ${ }_{\text {HadGEM2-ES }}$ with MAR HadCM3 $_{3}$. Therefore, we can assume that for warming climates, the uncertainty coming from RCMs in the modelled GrIS SMB changes remains below $10 \%$ of the projected SMB decrease if the same forcing is used.

\subsubsection{From GCMs}

Equation (1) allows us to estimate the changes in the GrIS SMB using only GCM outputs with an uncertainty of $35 \mathrm{GT} \mathrm{yr}^{-1}$ with respect to the MAR-based results if a 10yr running mean is applied. If we use the standard deviation around 30ENS as evaluation of the GCMs-based uncertainty in our SMB changes evaluation (see Fig. 7), this uncertainty is about 150 (resp. 450) $\mathrm{GT} \mathrm{yr}^{-1}$ in 2100 for the RCP45 (resp. RCP85) scenario and represents about 50\% of the projected mean SMB decrease. Figure 7 also shows that the uncertainty (of $\sim 0.7^{\circ} \mathrm{C}$ in 2100 ) in the projected global warming is amplified over Greenland due to the Arctic amplification (shown in Fig. 3a, b) and the non-linear response of the melt to rising temperatures over Greenland (shown in Fig. 6).

\subsubsection{From ice dynamics}

In addition to the uncertainties linked to the models/scenarios, it must be noted that these SMB projections 
do not take into account changes in ice dynamics and surface topography as described in Gregory and Huybrechts (2006). Since the GrIS topography is fixed during our simulations, we neglect the melt-elevation feedback, which should accelerate the melt increase (Helsen et al., 2012). Prolonged thinning of the ablation zone (as shown in Fig. 8) causes an additional warming for these areas, which should be lower in altitude if the topography could evolve during the simulation. Therefore, our projections are conservative and underestimate the GrIS SMB changes.

With the aim of estimating the uncertainties coming from this missing feedback in our SMB estimations, we have rerun MAR MIROC5 (RCP85) over 2080-2100 using three different ice sheet topographies based on the SMB changes over 20002080. The topography perturbations are $0.5,1.0$ and 1.5 times the 2000-2080 accumulated surface height anomaly coming

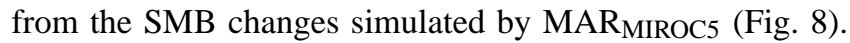
The SMB-based surface height anomalies are taken in respect to 1980-1999 and the new ice sheet topography is fixed over 2080-2100. The ice sheet dynamics should compensate, in part, the surface height decreases coming from the melt increase in the ablation zone, by redistributing the additional mass gained at the top of the ice sheet (coming from projected heavier snowfall) to the ice sheet margins. But, in our estimations of SMB-based surface height changes, we do not take into account changes in ice sheet topography over 20002080, and therefore, our 2000-2080 SMB changes estimations are likely to be underestimated. Therefore, we cannot conclude if a full coupled RCM-ice sheet model simulation would project over 2080-2100 topography changes above or below one times our accumulated 2000-2080 SMB-based surface height anomaly.

These sensitivity experiments show, in the ablation zone, a run-off increase and a snowfall decrease resulting from the conversion to rainfall due to the additional warming (see Fig. 8). In the accumulation zone, there is a small mass gain due to heavier snowfall but is not enough to compensate the additional surface mass loss in the ablation zone. Integrated over the whole ice sheet, the additional SMB changes resulting from the three lowerings of the ice sheet topography are respectively $-27,-57$ and $-83 \mathrm{GT} \mathrm{yr}^{-1}$ since the $2080-$ 2100 GrIS SMB anomaly is $-741 \mathrm{GT} \mathrm{yr}^{-1}$ in the control run. Therefore, taking into account ice topography changes in our simulations should add an additional surface mass loss of about $+8 \pm 5 \%$ in our SMB change estimations.

\section{Conclusions}

21 st century projections of the Greenland ice sheet SMB were carried out using the regional climate model MAR forced by climate change scenarios RCP 4.5 and RCP 8.5 and driven by the output of three GCMs from the CMIP5 database. The GCMs have been chosen for their ability to simulate the current climate (general circula- tion at $500 \mathrm{hPa}$ and $\mathrm{JJA}$ temperature at $700 \mathrm{hPa}$ ) over Greenland with respect to the ERA-Interim reanalysis. Most of the differences between MAR forced by ERAInterim (which we consider here as the best representation of the current SMB) and forced by CMIP5 GCMs over 1980-1999 are smaller than the uncertainty related to the estimate of the present-day GrIS SMB. Therefore, we can consider that MAR, when forced by these three CMIP5 models (CanESM2, MIROC5 and NorESM1$\mathrm{M})$, is able to realistically simulate the current SMB of the GrIS. However, these CMIP5 forced simulations do not reproduce the decrease of $\mathrm{SMB}$ that occurred in the 2000 s because this event is due to a decadal change in large-scale circulation (NAO) rather than a component of long-term climate change (Fettweis et al., 2013).

In terms of future projections, MAR simulates a substantial decrease of the SMB along the ice sheet margins due to increasing surface melt and a relatively smaller SMB increase in the interior of the ice sheet that follows from increased snowfall. No increase in the duration of the summer melt season is projected due to the enhanced winter snowfall, which dampens the melt increase in spring. Surface melt increases non-linearly with warming climates because of the expansion of bare ice zones in summer, which decreases the ice sheet meltwater refreezing capacity and enhances the positive melt/surface albedo feedback. In addition, since most of the precipitation should fall as rainfall instead of snowfall in summer, this contributes to increasing the surface melt. Finally, meltwater run-off sensitivity to warmer climates depends on the ability to simulate the current climate. If a model is too warm over current climate, the impact of a warmer climate is amplified since the response of melt to rising temperatures is not linear. This indicates that it is important to adequately reproduce the current climate before making future projections.

At the scale of the entire ice sheet, the increase of precipitation does not compensate the increase of run-off. MAR simulates a mean surface mass anomaly of about $\sim 200$ 400 (resp. $\sim 600-1200$ ) $\mathrm{GT} \mathrm{yr}^{-1}$ at the end of the 21 st century for the RCP 4.5 (resp. RCP 8.5) scenario with respect to the current climate. The large range in these MARbased future projections is due to the sensitivity of the used GCMs to a same GHG forcing. For the same increase in near-surface temperature, the MAR results are quasiindependent of the GCM used as forcing because no GCM projects changes in the large-scale atmospheric circulation over Greenland. This indicates that the main uncertainty in our study comes from the GCMs and that making future projections depends a lot on the chosen GCMs. However, the projected changes in respect to similar temperature anomalies are GCM independent.

By using snowfall and JJA $600 \mathrm{hPa}$ temperature anomalies from the forcing GCMs, we showed that the MAR-based SMB decrease at the scale of the whole ice sheet can be estimated using only GCMs outputs. This coarse estimation 
of the GrIS SMB changes shows that the uncertainty from the GCMs in our SMB estimations represent about $50 \%$ of the projected SMB changes. Furthermore, the CMIP5 ensemble mean projects a total eustatic sea level rise of about $\sim+4 \pm 2 \mathrm{~cm}$ (resp. $\sim+9 \pm 4$ ) in 2100 for the RCP4.5 (resp. RCP8.5) scenario.

It is important to note that these projections of sea level rise from the Greenland ice sheet surface mass loss do not take into account changes in ice dynamics and surface topography, which should amplify the deglaciation of Greenland due to the positive melt-elevation feedback. Our projections are assumed to be conservative and very likely underestimate the SMB decrease.

At the end of this century, according to the RCP8.5 scenario, accumulated anomalies of surface height due to SMB decrease could reach $100-200 \mathrm{~m}$ in some areas along the ice sheet margin. Sensitivity MAR experiments using perturbed ice sheet topographies suggest that these topographic changes could add an additional surface mass loss of about 5-15\% in our SMB projections over 2000-2100. This shows the necessity to couple RCMs with ice sheet models to better evaluate the feedbacks between surface thinning ice sheet area decline and changes to the SMB (Helsen et al., 2012). This manuscript reveals that MIROC5 seems to be one of the best forcings to test such a coupling over Greenland. The RCMs (vs. GSMs) with realistic melt physics and high horizontal resolution remain vital for doing this kind of coupling knowing that the ice sheet models request SMB inputs at spatial resolutions lower than $10 \mathrm{~km}$. However, for long-time future projections (e.g. 500-1000 yr), RCMs coupled to an ice sheet are not able to evaluate the impact of a GrIS depletion to the general circulation and THC. In this case, it is preferable to use GCMs to achieve this kind of coupling.

\section{Supplementary material related to this article is available online at: http://www.the-cryosphere.net/7/469/ 2013/tc-7-469-2013-supplement.pdf.}

Acknowledgements. Xavier Fettweis is a postdoctoral researcher of the Belgian National Fund for Scientific Research. For their roles in producing, coordinating, and making available the CMIP5 model output, we acknowledge the climate modelling groups (listed in Table 1 of this paper), the World Climate Research Programme's (WCRP) Working Group on Coupled Modelling (WGCM), and the Global Organization for Earth System Science Portals (GO-ESSP). We thank Jamie Rae for having provided the ECHAM5 and HadCM3 outputs, Jonathan Gregory for his helpful comments and both reviewers for their very useful and constructive reviews which greatly improved our paper. Finally, this work was partly supported by funding from the ICE2SEA programme from the European Union 7th Framework Programme (FP7), grant number 226375 (ice2sea contribution number 098). Marco Tedesco's work was supported by the NSF grant \# ARC0909388.

Edited by: J. L. Bamber

\section{References}

Bamber, J. L., Layberry, R. L., and Gogenini, S. P.: A new ice thickness and bed data set for the Greenland ice sheet 1: measurement, data reduction, and errors, J. Geophys. Res., 106, 33773-33780, 2001.

Belleflamme, A., Fettweis, X., Lang, C., and Erpicum, M.: Current and future atmospheric circulation at $500 \mathrm{hPa}$ over Greenland simulated by the CMIP3 and CMIP5 global models, Clim. Dynam., doi:10.1007/s00382-012-1538-2, accepted, 2012.

Bengtsson, L., Koumoutsaris, S., and Hodges, K.: Large-scale surface mass balance of ice sheets from a comprehensive atmospheric model, Surv. Geophys., 32, 459-474, 2011.

Box, J. E., Bromwich, D. H., and Bai, L.-S.: Greenland ice sheet surface mass balance for 1991-2000: application of Polar MM5 mesoscale model and in-situ data, J. Geophys. Res., 109, D16105, doi:10.1029/2003JD004451, 2004.

Box, J. E., Fettweis, X., Stroeve, J. C., Tedesco, M., Hall, D. K., and Steffen, K.: Greenland ice sheet albedo feedback: thermodynamics and atmospheric drivers, The Cryosphere, 6, 821-839, doi:10.5194/tc-6-821-2012, 2012.

Brun, E., David, P., Sudul, M., and Brunot, G.: A numerical model to simulate snowcover stratigraphy for operational avalanche forecasting, J. Glaciol., 38, 13-22, 1992.

Dee, D. P., Uppala, S. M., Simmons, A. J., Berrisford, P., Poli, P., Kobayashi, S., Andrae, U., Balmaseda, M. A., Balsamo, G., Bauer, P., Bechtold, P., Beljaars, A. C. M., van de Berg, L., Bidlot, J., Bormann, N., Delsol, C., Dragani, R., Fuentes, M., Geer, A. J., Haimberger, L., Healy, S. B., Hersbach, H., Hólm, E. V., Isaksen, L., Kållberg, P., Köhler, M., Matricardi, M., McNally, A. P., Monge-Sanz, B. M., Morcrette, J.-J., Park, B.-K., Peubey, C., de Rosnay, P., Tavolato, C., Thépaut, J.-N., and Vitart, F.: The ERA-Interim reanalysis: configuration and performance of the data assimilation system, Quart. J. R. Meteorol. Soc., 137, 553-597, 2011.

Fettweis, X.: Reconstruction of the 1979-2006 Greenland ice sheet surface mass balance using the regional climate model MAR, The Cryosphere, 1, 21-40, doi:10.5194/tc-1-21-2007, 2007.

Fettweis, X., Gallée, H., Lefebre, L., and van Ypersele, J.-P.: Greenland surface mass balance simulated by a regional climate model and comparison with satellite derived data in 1990-1991, Clim. Dynam., 24, 623-640, doi:10.1007/s00382-005-0010-y, 2005.

Fettweis, X., Gallée, H., Lefebre, L., and van Ypersele, J.-P.: The 1988-2003 Greenland ice sheet melt extent by passive microwave satellite data and a regional climate model, Clim. Dynam., 27, 531-541, doi:10.1007/s00382-006-0150-8, 2006.

Fettweis, X., Hanna, E., Gallée, H., Huybrechts, P., and Erpicum, M.: Estimation of the Greenland ice sheet surface mass balance for the 20th and 21st centuries, The Cryosphere, 2, 117129, doi:10.5194/tc-2-117-2008, 2008.

Fettweis, X., Mabille, G., Erpicum, M., Nicolay, S., and van den Broeke, M.: The 1958-2009 Greenland ice sheet surface melt and the mid-tropospheric atmospheric circulation, Clim. Dynam., 36, 139-159, doi:10.1007/s00382-010-0772-8, 2011a.

Fettweis, X., Tedesco, M., van den Broeke, M., and Ettema, J.: Melting trends over the Greenland ice sheet (1958-2009) from spaceborne microwave data and regional climate models, The Cryosphere, 5, 359-375, doi:10.5194/tc-5-359-2011, 2011 b.

Fettweis, X., Belleflamme, A., Erpicum, M., Franco, B., and Nicolay, S.: Estimation of the Sea Level Rise by 2100 Resulting from 
Changes in the Surface Mass Balance of the Greenland Ice Sheet, Climate Change - Geophysical Foundations and Ecological Effects, edited by: Blanco, J. and Kheradmand, H., ISBN: 978-953307-419-1, InTech, 2011c.

Fettweis, X., Hanna, E., Lang, C., Belleflamme, A., Erpicum, M., and Gallé, H.: Brief communication "Important role of the midtropospheric atmospheric circulation in the recent surface melt increase over the Greenland ice sheet", The Cryosphere, 7, 241248, doi:10.5194/tc-7-241-2013, 2013.

Franco, B., Fettweis, X., Erpicum, M., and Nicolay, S.: Present and future climates of the Greenland ice sheet according to the IPCC AR4 models, Clim. Dynam., 36, 1897-1918, doi:10.1007/s00382-010-0779-1, 2011.

Franco, B., Fettweis, X., Lang, C., and Erpicum, M.: Impact of spatial resolution on the modelling of the Greenland ice sheet surface mass balance between 1990-2010, using the regional climate model MAR, The Cryosphere, 6, 695-711, doi:10.5194/tc6-695-2012, 2012.

Franco, B., Fettweis, X., and Erpicum, M.: Future projections of the Greenland ice sheet energy balance driving the surface melt, developed using the regional climate MAR model, The Cryosphere, 7, 1-18, doi:10.5194/tc-7-1-2013, 2013.

Gallée, H. and Schayes, G.: Development of a three-dimensional meso- $\gamma$ primitive equations model, Mon. Weather Rev., 122, 671-685, 1994.

Gallée, H., Guyomarc'h, G., and Brun, E.: Impact of the snow drift on the Antarctic ice sheet surface mass balance: possible sensitivity to snow-surface properties, Bound.-Lay. Meteorol., 99, 1-19, 2001.

Goelzer, H., Huybrechts, P., Furst, J. J., Andersen, M. L., Edwards, T. L., Fettweis, X., Nick, F. M., Payne, A. J., and Shannon, S.: Sensitivity of Greenland ice sheet projections to model formulations, J. Glaciol., in revision, 2012.

Graversen R., Drijfhout, S., Hazeleger, W., van de Wal, R., Bintanja, R., and Helsen H.: Greenland's contribution to global sealevel rise by the end of the 21 st century, Clim. Dynam., 37, 14271442, 2010.

Gregory, J. and Huybrechts, P.: Ice-sheet contributions to future sealevel change, Philos. T. R. Soc. A, 364, 1709-1731, 2006.

Hakuba, M. Z., D. Folini, M. Wild, and C. Schär: Impact of Greenland's topographic height on precipitation and snow accumulation in idealized simulations, J. Geophys. Res., 117, D09107, doi:10.1029/2011JD017052, 2012.

Hanna, E., Cappelen, J., Fettweis, X., Huybrechts, P., Luckman, A., and Ribergaard, M. H.: Hydrologic response of the Greenland ice sheet: the role of oceanographic warming, Hydrol. Process., 23, 7-30, 2009.

Hanna, E., Jones, J. M., Cappelen, J., Mernild, S. H., Wood, L., Steffen, K., and Huybrechts, P.: The influence of North Atlantic atmospheric and oceanic forcing effects on 1900-2010 Greenland summer climate and ice melt/runoff, Int. J. Climatol., doi:10.1002/joc.3475, 2012.

Helsen, M. M., van de Wal, R. S. W., van den Broeke, M. R., van de Berg, W. J., and Oerlemans, J.: Coupling of climate models and ice sheet models by surface mass balance gradients: application to the Greenland Ice Sheet, The Cryosphere, 6, 255-272, doi:10.5194/tc-6-255-2012, 2012.

IPCC: Climate Change 2007: The Physical Science Basis, Contribution of Working Group I to the Fourth Assessment Report of the Intergovernmental Panel on Climate Change, edited by: Solomon, S., Qin, D., Manning, M., Chen, Z., Marquis, M., Averyt, K. B., Tignor, M., and Miller, H. L., Cambridge University Press, Cambridge, UK and New York, NY, USA, 2007.

Lefebre, F., Gallée, H., van Ypersele, J., and Greuell, W.: Modeling of snow and ice melt at ETH-camp (West Greenland): a study of surface albedo, J. Geophys. Res., 108, 4231, doi:10.1029/2001JD001160, 2003.

Lefebre, F., Fettweis, X., Gallée, H., van Ypersele, J., Marbaix, P., Greuell, W., and Calanca, P.: Evaluation of a high-resolution regional climate simulation over Greenland, Clim. Dynam., 25, 99-116, doi:10.1007/s00382-005-0005-8, 2005.

Lenaerts, J. T. M., van den Broeke, M. R., van Angelen, J. H., van Meijgaard, E., and Déry, S. J.: Drifting snow climate of the Greenland ice sheet: a study with a regional climate model, The Cryosphere, 6, 891-899, doi:10.5194/tc-6-891-2012, 2012.

Lucas-Picher, P., Wulff-Nielsen, M., Christensen, J. H., Adalgeirsdottir, G., Mottram, R., and Simonsen, S. B.: Very high resolution regional climate model simulations over Greenland: Identifying added value, J. Geophys. Res., 117, D02108, doi:10.1029/2011JD016267, 2012.

Mernild, S. H., Liston, G. E., and Hasholt, B.: East Greenland freshwater run-off to the Greenland-Iceland-Norwegian Seas 1999 2004 and 2071-2100, Hydrol. Process., 22, 4571-4586, 2008.

Mernild, S. H., Liston, G. E., Hiemstra, C. A., and Christensen, J. H.: Greenland ice sheet surface mass-balance modeling in a 131-yr perspective, 1950-2080, J. Hydrometeorol., 11, 3-25, doi:10.1175/2009JHM1140.1, 2010.

Moss, R. H., Edmonds, J. A., Hibbard, K., Manning, M., Rose, S. K., van Vuuren, D. P., Carter, T. R., Emori, S., Kainuma, M., Kram, T., Meehl, G., Mitchell, J., Nakicenovic, N., Riahi, K., Smith, S., Stouffer, R. J., Thomson, A., Weyant, J., and Wilbanks, T.: The next generation of scenarios for climate change research and assessment, Nature, 463, 747-756, doi:10.1038/nature08823, 2010.

Mote, T. L.: Estimation of runoff rates, mass balance, and elevation changes on the Greenland ice sheet from passive microwave observations, J. Geophys. Res., 108, 4056, doi:10.1029/2001JD002032, 2003.

Nick, F. M., Vieli, A., Howat, I. M., and Joughin, I.: Large-scale changes in Greenland outlet glacier dynamics triggered at the terminus, Nature Geosci., 2, 110-114, doi:10.1038/ngeo394, 2009.

Rae, J. G. L., Aalgeirsdóttir, G., Edwards, T. L., Fettweis, X., Gregory, J. M., Hewitt, H. T., Lowe, J. A., Lucas-Picher, P., Mottram, R. H., Payne, A. J., Ridley, J. K., Shannon, S. R., van de Berg, W. J., van de Wal, R. S. W., and van den Broeke, M. R.: Greenland ice sheet surface mass balance: evaluating simulations and making projections with regional climate models, The Cryosphere, 6 , 1275-1294, doi:10.5194/tc-6-1275-2012, 2012.

Rignot, E., Box, J. E., Burgess, E., and Hanna, E.: Mass balance of the Greenland ice sheet from 1958 to 2007 , Geophys. Res. Lett., 35, L20502, doi:10.1029/2008GL035417, 2008.

Rignot, E., Velicogna, I., van den Broeke, M. R., Monaghan, A., and Lenaerts, J.: Acceleration of the contribution of the Greenland and Antarctic ice sheets to sea level rise, Geophys. Res. Lett., 38, L05503, doi:10.1029/2011GL046583, 2011.

Robinson, A., Calov, R., and Ganopolski, A.: Multistability and critical thresholds of the Greenland ice sheet, Nat. Clim. Change, 2, 429-432, doi:10.1038/NCLIMATE1449, 2012. 
Schuenemann, K. C. and Cassano, J. J.: Changes in synoptic weather patterns and Greenland precipitation in the 20th and 21st centuries: 2 . Analysis of 21 st century atmospheric changes using self-organizing maps, J. Geophys. Res., 115, D05108, doi:10.1029/2009JD011706, 2010.

Screen, J. A. and Simmonds, I.: Erroneous Arctic temperature trends in the ERA-40 reanalysis: a closer look, J. Clim., 24, 2620-2627, doi:10.1175/2010JCLI4054.1, 2011.

Serreze, M. C., Barrett, A. P., Stroeve, J. C., Kindig, D. N., and Holland, M. M.: The emergence of surface-based Arctic amplification, The Cryosphere, 3, 11-19, doi:10.5194/tc-3-11-2009, 2009.

Sundal, A. V., Shepherd, A., Nienow, P., Hanna, E., Palmer, S., and Huybrechts, P.: Melt-induced speed-up of Greenland ice sheet offset by efficient subglacial drainage, Nature, 469, 521-524, doi:10.1038/nature09740, 2011.

Swingedouw, D., Mignot, J., Braconnot, P., Mosquet, E., Kageyama, M. and Alkama, R.: Impact of freshwater release in the North Atlantic under different climate conditions in an OAGCM, J. Clim., 22, 6377-6403, 2009.

Tedesco, M., Fettweis, X., van den Broeke, M., van de Wal, R., Smeets, P., van de Berg, W. J., Serreze, M., and Box, J.: The role of albedo and accumulation in the 2010 melting record in Greenland, Environ. Res. Lett., 6, 014005, doi:10.1088/17489326/6/1/014005, 2011.

Tedesco, M., Luthje, M., Steffen, K., Steiner, N., Fettweis, X., Willis, I., Bayou, N., and Banwell, A.: Measurement and modeling of ablation of the bottom of supraglacial lakes in Western Greenland, Geophys. Res. Lett., 39, L02502, doi:10.1029/2011GL049882, 2012. van Angelen, J. H., Lenaerts, J. T. M., Lhermitte, S., Fettweis, X., Kuipers Munneke, P., van den Broeke, M. R., van Meijgaard, E., and Smeets, C. J. P. P.: Sensitivity of Greenland Ice Sheet surface mass balance to surface albedo parameterization: a study with a regional climate model, The Cryosphere, 6, 1175-1186, doi:10.5194/tc-6-1175-2012, 2012a.

van Angelen, J. H., Lenaerts, J. T. M., van den Broeke, M. R., Fettweis, X., and van Meijgaard, E.: Loss of refreezing capacity accelerates 21 st century Greenland mass loss, Geophys. Res. Lett., submitted, 2013.

van den Broeke, M. R., Bamber, J., Ettema, J., Rignot, E., Schrama, E., van de Berg, W. J., van Meijgaard, E., Velicogna, I., and Wouters, B.: Partitioning recent Greenland mass loss, Science, 326, 984-986, 2009.

Vernon, C. L., Bamber, J. L., Box, J. E., van den Broeke, M. R., Fettweis, X., Hanna, E., and Huybrechts, P.: Surface mass balance model intercomparison for the Greenland ice sheet, The Cryosphere Discuss., 6, 3999-4036, doi:10.5194/tcd-6-39992012, 2012.

Vizcaino, M., Mikolajewicz, U., Jungclaus, J., and Schurgers, G.: Climate modification by future ice sheet changes and consequences for ice sheet mass balance, Clim. Dynam., 34, 301-324, 2010 .

Weijer, W., Maltrud, M. E., Hecht, M. W., Dijkstra, H. A., and M. A. Kliphuis: Response of the Atlantic Ocean circulation to Greenland Ice Sheet melting in a strongly-eddying ocean model, Geophys. Res. Lett., 39, L09606, doi:10.1029/2012GL051611, 2012.

Zwally, J. H., Abdalati, W., Herring, T., Larson, K., Saba, J., and Steffen, K.: Surface melt-induced acceleration of Greenland icesheet flow, Science, 297, 218-222, 2002. 